\title{
Aproximación a los nuevos conceptos sobre violencia y acoso en el trabajo a partir de la aprobación del Convenio OIT 190
}

\author{
An initial approach to the new concepts of violence and \\ harassment at work introduced by the ILO Convention 190
}

\author{
María Pons Carmena ${ }^{* *}$ \\ Universitat de València \\ ORCID ID: 0000-0002-1378-8840
}

Recibido: 25/2/2020

Aceptado: 3/4/2020

doi: https://doi.org/10.20318/labos.2020.5538

Resumen: El Convenio OIT 190 sobre la eliminación de la violencia y el acoso en el mundo del trabajo adoptado en 2019 establece un nuevo concepto sobre violencia y acoso de carácter amplio y general. Por ello se requiere revisar los múltiples conceptos existentes en nuestra legislación, así como las actuales interpretaciones judiciales y doctrinales de los mismos, con especial hincapié en lo que se denomina acoso moral que no está definido legalmente. La nueva norma internacional va a requerir replantearse la concepción de la violencia y el acoso por razón de género como subcategoría de la violencia y acoso por motivos discriminatorios y, también, la adecuación de los conceptos de trabajador y del lugar de trabajo como ámbitos de aplicación de la normativa con respecto a la prevención, protección y tutela que ofrece la misma frente a la violencia y el acoso en el ámbito laboral.

Palabras clave: violencia y acoso en el trabajo, Convenio OIT, violencia de género, acoso moral, riesgos psicosociales.

Abstract: The ILO Convention 190 on the elimination of violence and harassment at work adopted in 2019 has introduced a new, wide and general concept of violence and harassment. Therefore, it becomes necessary to re-examine the actual legal concepts that exist and their judicial and doctrinal interpretation. Since moral harassment is not defined in the Spanish legal system, a special attention has to be paid to this type of harassment. The new international norm requires as well the revision of the concept of gender-based harassment, established as a subcategory of violence and harassment based on discriminatory reasons. Also, the concepts of worker and workplace, as references of the scope of application of the norm in respect to its legal prevention and protection, should be reexamined in the light of the new international legislation.

Keywords: violence and harassment at work, ILO Convention, gender-based violence, moral harassment, psychosocial risks.

\footnotetext{
"Trabajo realizado en el marco del I+D de Generación del Conocimiento sobre Violencia, Trabajo y Género (VITRAGE), Ref. PGC2018-094912-B-I00, del Programa Estatal de Generación del Conocimiento y fortalecimiento científico y tecnológico del sistema del I+D+i del Ministerio de Ciencia, Innovación e Universidades.

*mponsc@uv.es
} 


\section{La aprobación de una nueva norma internacional y sus posibles repercusiones}

El pasado 21 de junio de 2019, en el marco de la $108^{a}$ reunión de la Conferencia Internacional del Trabajo, se aprobó el Convenio $n^{\circ} 190$ de la OIT sobre violencia y acoso en el mundo del trabajo que se presentó junto a su Recomendación complementaria ( $n^{\circ}$ 206). Dada la prolongada abstinencia normativa de la $\mathrm{OIT}^{1}$, la mera adopción de un nuevo Convenio es un hecho en sí mismo relevante, especialmente en estas épocas actuales en las que, en muchas ocasiones, se cuestiona la autoridad de la gran dama de 1919: se discute la convivencia de las normas de la OIT con otro tipo de normas privadas de aplicación transnacional, y no necesariamente imperativas, como nueva forma de protección de los derechos sociales en el espacio global. El balance suele ser mediocre².

Conviene una nueva norma internacional sobre violencia y acoso en el trabajo después de, al menos, dos años de negociaciones en el seno de la $\mathrm{OIT}^{3}$ : un Convenio de carácter técnico y una Recomendación que lo complementa. Conductas como la violencia, la intimidación, el acoso y otros comportamientos abusivos han existido siempre pero en la actualidad están cobrando una mayor visibilidad y renovada atención tanto a nivel internacional como a nivel nacional; en ambos casos por motivos similares. Por un lado, porque afectan a derechos esenciales (fundamentales) de la persona como la dignidad, la integridad física y moral, el honor y la salud; pues los comportamientos violentos y/o abusivos tienen efectos "pluriofensivos". Por otro lado, porque a pesar de la existencia de problemáticas diversas según países, la realidad es compartida: los mecanismos de prevención están fallando, quizás porque no son jurídicamente vinculantes, o porque pretenden sancionar más que prevenir o, directamente, porque no existen y, si existen, no se aplican. A su vez, los mecanismos de tutela, principalmente la judicial, muestran un panorama decepcionante tanto en cuanto al número de asuntos que llegan a plantearse por esta vía, con respecto a la realidad del fenómeno -muy pocos 5 -, como los que, de tramitarse, se pronuncian en favor de las víctimas de las situaciones de acoso y violencia, resarciendo adecuadamente por los daños causados.

El tratamiento normativo de la violencia y acoso en el trabajo no es, desde luego, novedoso, ni a nivel nacional, ni europeo, ni tampoco -parcialmente- a nivel internacional ${ }^{6}$ y existen numerosos estudios doctrinales que así lo manifiestan. Interesa analizar como podría afectarnos una próxima ratificación de esta nueva norma internacional7, el Convenio OIT 190, que es el primer

\footnotetext{
${ }^{1}$ Sobre las causas de la prolongada abstinencia normativa de la OIT, vid., OJEDA AVILÉS, A., "Del mundialismo a la globalización. Un balance de los convenios OIT y su proyección futura”, Revista de Trabajo y Seguridad Social, CEF, 434, 2019 , p. 30.

${ }^{2}$ SANGUINETI RAYMOND, W., "Las cadenas mundiales de producción y la construcción de un derecho del trabajo sin fronteras", Ponencia Inaugural del XXIX Congreso Anual de la Asociación Española de Derecho del Trabajo y de la Seguridad Social sobre "El futuro del trabajo: cien años de OIT", Salamanca, 30 y 31 de mayo de 2019, pp. 31-2. Cuestión distinta sería el facilitar el uso de las normas de la OIT por actores privados y no estatales. En este sentido, MAUPAIN, F., The future of the International Labour Organization in the global economy, Oxford, Hart Publishing, 2013.

${ }^{3}$ Véanse los Informes de la OIT V (1) de 2018 y (2 A) y (2B) de 2019 sobre "Acabar con la violencia y el acoso en el mundo del trabajo".

${ }^{4}$ MONTOYA MELGAR, A., "El acoso en el trabajo y su encuadramiento jurídico", Civitas, Revista Española de Derecho del Trabajo no 140, 2008, p. 756; Vid., VALDÉS DAL-RÉ, F., "Derecho constitucional y violencia en el trabajo en España”, Revista Internacional y comparada de Relaciones laborales y derecho del Empleo, Vol. 1, núm. 4, octubre-diciembre de 2013, p. 8.

${ }^{5}$ Vid., Observatorio Vasco sobre Acoso y Discriminación. Estudio de la doctrina judicial en materia de acoso en el Trabajo, Tirant Lo Blanch, 2019; MOLINA NAVARRETE, C., "Del acoso moral (mobbing) al ciberacoso en el trabajo (network mobbing): viejas y nuevas formas de violencia laboral como riesgo psicosocial en la reciente doctrina judicial”, Revista de Trabajo y Seguridad Social, CEF, 437-438 (agosto-septiembre 2019), pp. 144-146.

${ }^{6}$ Sobre los Convenios de la OIT ( $n^{\circ} 155$ y no 187 ) que tratan sobre cuestiones preventivas en los que pueden incluirse los riesgos psicosociales Vid., BALLESTER PASTOR, M. A., "La política de la OIT y de la Unión Europea sobre la salud y riesgos psicosociales", Revista Internacional y Comparada de Relaciones Laborales, ADAPT University Press, volumen 1, no 4, octubre-diciembre 2013, pp. 15 y ss.; MORALES RAMÍREZ, M. A., “Aproximación al acoso laboral desde la legislación comparada”, Boletín Mexicano de Derecho Comparado, nueva serie, año XLIX, núm. 147, septiembre-diciembre de 2016, pp. 71-98.

7 Según lo dispuesto en el art. 14.2 del Convenio OIT 190, éste entrará en vigor 12 meses después de la fecha en las que las ratificaciones de dos Miembros hayan sido registradas por el Director General. “Desde dicho momento, el presente Convenio entrará
} 
instrumento normativo de carácter internacional que trata sobre la violencia y acoso en el trabajo de forma global e integral, sobre los conceptos normativos existentes en nuestra legislación, así como sobre las actuales interpretaciones judiciales y doctrinales de los mismos, con especial hincapié en lo que se denomina acoso moral. Ha de prestarse especial atención también a la concepción de la violencia y el acoso en el mundo del trabajo como riesgo psicosocial que afecta a la dignidad de las personas. Tanto el Convenio 190 OIT como la Recomendación que lo acompańa inciden de forma significativa en el tratamiento de la violencia y acoso en el trabajo como materia indispensable e inseparable de la prevención y gestión de la seguridad y salud en el trabajo. Aunque no se dice expresamente, el objetivo de la normativa responde a la necesidad de "fomentar lugares de trabajo seguros, salubres, armoniosos y libres de violencia y acoso". Así se menciona en el apartado 23.g de la Recomendación, que aconseja a los Miembros financiar, elaborar, aplicar y difundir campañas públicas destinadas a fomentar lugares de trabajo con estas características.

\section{Estado actual de la regulación sobre violencia y acoso en el trabajo: definiciones y clasifica- ciones}

\subsection{Normativa interna sobre violencia y acoso en el trabajo}

A nivel interno, en el plano del derecho material, contamos con varias normas que tratan sobre violencia y acoso en el trabajo; son las siguientes:

a) En términos generales, el Estatuto de los trabajadores (ET) reconoce el derecho de los trabajadores en la relación de trabajo "al respecto de su intimidad y la consideración debida a su dignidad, comprendida la protección frente al acoso por razón de origen racial o étnico, religión o convicciones, discapacidad, edad u orientación sexual, y frente al acoso sexual y al acoso por razón de sexo" (art. 4). A su vez, el artículo 54.2.g ET considera incumplimiento contractual el acoso por razón de origen racial o étnico, religión, convicciones, discapacidad, edad u orientación sexual al empresario o a las personas que trabajan en la empresa.

Por su parte, el Estatuto Básico del Empleado Público, aprobado por RD Legislativo 5/2015, tipifica como faltas disciplinarias muy graves de los empleados públicos, por un lado, "el acoso por razón de origen racial o étnico, religión o convicciones, discapacidad, edad u orientación sexual y el acoso moral, sexual y por razón de sexo" (art. 95.2.b); y por otro, "el acoso laboral" (art. 95.2.o).

b) En términos más concretos, ha de destacarse la Ley 62/2003 de Medidas Fiscales Administrativas y del Orden social, que incorporó al ordenamiento español las Directivas: 2000/43, relativa a la aplicación del principio de igualdad de trato de las personas independientemente de su origen racial o étnico; y la 2000/78 sobre el establecimiento de un marco general para la igualdad de trato en el empleo y en la ocupación, que pretende luchar contra las discriminaciones basadas en la religión o convicciones, la discapacidad, la edad y la orientación sexual. Esta Ley 62/2003 definió, por vez primera en nuestro ordenamiento, el acoso discriminatorio como "toda conducta no deseada, relacionada con el origen racial o étnico, la religión o convicciones, la discapacidad, la edad, la orientación

en vigor, para cada miembro, 12 meses después de la fecha de registro de su ratificación” art. 14.3 Convenio OIT 190. Hasta la fecha (mayo 2020) no se ha ratificado el Convenio OIT 190 en ningún país. 
sexual de una persona, que tenga como objetivo o consecuencia atentar contra su dignidad y crear un entorno intimidatorio, humillante u ofensivo" (art. 28.1).

c) La Ley Orgánica de Igualdad 3/2007 (LOI) define el acoso sexual como "cualquier comportamiento, verbal o físico, de naturaleza sexual que tenga el propósito o produzca el efecto de atentar contra la dignidad de una persona, en particular cuando se crea un entorno, intimidatorio, degradante u ofensivo" (art. 7.1) y el acoso por razón de sexo como "cualquier comportamiento realizado en función del sexo de una persona, con el propósito o el efecto de atentar contra su dignidad y de crear un entorno intimidatorio, degradante u ofensivo" (art. 7.2).

d) La Ley Orgánica 1/2004, de 28 de diciembre, de protección integral contra la violencia de género, cuya finalidad es atajar y erradicar la violencia de género con carácter integral y multidisciplinar, incorporando medidas preventivas y de sensibilización, define esta forma de violencia en su art. 1.3: comprende todo acto de violencia física y psicológica, incluidas las agresiones a la libertad sexual, las amenazas, las coacciones o la privación arbitraria de libertad. En esta norma, la violencia de género se configura como una manifestación de discriminación, de la situación de desigualdad histórica de los hombres sobre las mujeres (art. 1.1) ${ }^{8}$. Por indicación de la DA $7^{\circ}$ de esta Ley, se modificaron los siguientes artículos del ET: art. 37.7 (jornada); art. 40.4 (traslado o cambio de puesto de trabajo); art. 45.1.n (suspensión del contrato de trabajo); art. 48.10 (duración de la suspensión contractual); art. 49.1.m (extinción del contrato); 52.d.2 párrafo (despido objetivo) y art. 55.5.b (efectos del despido disciplinario).

e) El Real Decreto Legislativo 1/2013 sobre derechos de las personas con discapacidad hace referencia al acoso discriminatorio en personas con discapacidad en su art. 2.f, definiendo este como "toda conducta no deseada relacionada con la discapacidad de una persona que tenga como objetivo o consecuencia atentar contra su dignidad o crear un entorno intimidatorio, hostil, degradante, humillante u ofensivo".

f) El Real Decreto-Ley 6/2019, de 1 de marzo, sobre medidas urgentes de garantía de la igualdad de trato y de oportunidades entre mujeres y hombres en el empleo y la ocupación incide en la prevención del acoso sexual y del acoso por razón de sexo, y obliga a la puesta en marcha de planes de igualdad en empresas de más de 50 trabajadores a partir de 2022 y, además, prevé un nuevo permiso y formas de ordenación del tiempo de trabajo por razón de violencia de género sobre la mujer funcionaria (art. 49.d EBEP).

En el plano de la tutela administrativa ante situaciones de violencia y acoso en el trabajo, el Real Decreto Legislativo 5/2000 (LISOS) prevé como infracciones muy graves: 1.- el acoso sexual (art. 8.13)'; 2.- el acoso discriminatorio, que define como "acoso por razón de origen racial o étnico, religioso o convicciones, discapacidad, edad y orientación social y el acoso por razón de sexo, cuando se produzcan dentro del ámbito a que alcanzan las facultades de dirección empresarial, cualquiera que sea el sujeto activo del mismo, siempre que, conocido por el empresario, éste no hubiera adoptado las medidas necesarias para impedirlo" (art. 8.13 bis); 3.- y, en general, "los actos del empresario que fueren contrarios al respeto de la intimidad y consideración debida a la digni-

\footnotetext{
${ }^{8}$ Limitándose su ámbito de aplicación a la violencia que se ejerce sobre las mujeres por parte de quienes sean o hayan sido sus cónyuges o de quienes estén o hayan estado ligadas a ellas por relaciones similares de afectividad, aún sin convivencia (art. 1.1). Como ha señalado GARCÍA TESTAL, esto no ocurre en otras normas autonómicas, que suelen establecer conceptos más amplios de violencia de género, amparando a otros sujetos distintos de la mujer pero dependientes de ella; en cualquier contexto o ámbito... En Derechos de las trabajadoras víctimas de la violencia de género, Colección laboral no 229, Tirant Lo Blanch, Valencia, 2014, pp. 118-119.

${ }^{9}$ Art. 8.13 LISOS: "El acoso sexual, cuando se produzca dentro del ámbito a que alcanzan las facultades de decisión empresarial, cualquiera que sea el sujeto activo de la misma".
} 
dad de los trabajadores" (art. 8.11), pudiéndose encuadrar en este último artículo, el denominado acoso moral ${ }^{10}$. La comisión de estas infracciones da lugar a unas responsabilidades empresariales específicas -básicamente ser excluidos por un periodo de 6 meses a dos ańos y/o perder ayudas y bonificaciones al empleo y la obligación de elaborar un plan de igualdad aún no estando legalmente obligado a ello ${ }^{11}-y$, también, a la correspondiente sanción administrativa general -multa- prevista en la LISOS para las infracciones muy graves en materia de relaciones laborales (art. 40.1). En caso de que las conductas de violencia o acoso pudiesen ser constitutivas de delito, y para salvaguardar el principio non bis in idem, el funcionario actuante habrá de informar de ello al Jefe de la Inspección de Trabajo y éste, de estimar la concurrencia de ilícito penal, lo comunicará al órgano competente para resolver (art. 5.1 RD 928/1998). En este sentido, la ITSS está obligada a incoar de oficio el proceso penal (art. 22 Ley 23/2015 de la ITSS).

El Código Penal tipifica varios tipos de acoso, entre estos, los siguientes: 1.- el acoso de acecho o predatorio (art. 172 ter); 2.- el acoso laboral (art. 173.1 segundo párrafo, previsto a partir de la reforma del Código Penal por LO 5/2010), está configurado por su ubicación como un atentado a la integridad moral ${ }^{12}$. Cuando el acoso tiene lugar "en el ámbito de cualquier relación laboral o funcionarial" y "prevaliéndose de la relación de superioridad", constituirá grave acoso "cuando se realicen de forma reiterada ${ }^{13}$ actos hostiles o humillantes aun cuando no lleguen a constituir trato degradante". Se prevé la pena de prisión de seis meses a dos años; 3.- el acoso sexual está comprendido entre los delitos contra la libertad y la indemnidad sexuales (art. 184). Los elementos del tipo son: 1.- solicitud sexual (no se exige que se obtenga el favor sexual pero sí que se coloque a la víctima en una situación objetiva y gravemente intimidatoria, hostil o humillante); 2.- es necesario que exista una relación en el ámbito laboral, docente o de prestación de servicios entre el sujeto activo y el pasivo; 3.- provocación de situación intimidatoria, hostil o humillante. La pena prevista para el tipo básico es de tres a cinco meses de prisión o multa de seis a diez meses. Las situaciones de superioridad laboral docente o jerárquica y las especiales circunstancia de la víctima (edad, vulnerabilidad o enfermedad) conllevan penas mayores (subtipos agravados, arts. 184.2 y 184.3).

El Código Penal actual (versión LO 1/2015), recoge las nuevas redacciones establecidas por la LO 1/2004 relativas a las medidas de protección contra la violencia de género. En concreto, destacan las siguientes disposiciones: art. 153 sobre malos tratos; art. 171 apartados 4, 5 y 6 sobre amenazas; art. 172.2 coacciones; art. 468 sobre quebrantamiento de condena; art. 620 sobre vejaciones leves, entre otros.

Ha de señalarse que en nuestra norma fundamental en materia de seguridad y salud laborales, la Ley 31/1995 de Prevención de Riesgos Laborales -LPRL-, no se encuentran referencias expresas a la violencia y al acoso en el trabajo, como riesgo psicosocial que es. La ITSS llegó a dictaminar (Criterio técnico 34/2003) que el acoso laboral quedaba fuera del ámbito sustantivo y sancionador de la ITSS. Ello no obstante, una amplia doctrina judicial y académica, que ha acabado siendo respaldada por el TC, viene considerando, no sólo que el acoso y demás riesgos psicosociales son dańos derivados del trabajo (art. 4.3 LPRL), sino también que el deber de protección del empresario (art.

\footnotetext{
${ }^{10}$ Vid., SSTSJ Madrid 27 de junio y 3 diciembre de 2007.

${ }^{11}$ Vid., art. 46 bis LISOS.

${ }^{12} \mathrm{La}$ integridad moral deberá ser entendida como el derecho a ser tratado como persona y no como cosa; el derecho a no ser sometido a comportamientos que, dirigidos a humillar y degradas a la persona, la utilicen como mero instrumento en manos del sujeto activo. PÉREZ MACHÍO, A., Mobbing y Derecho Penal, Tirant Lo Blanch, Valencia, p. 100. Véase también, ACALE SÁNCHEZ, M., "El concepto poliédrico de acoso en el trabajo en el Código Penal: luces y sombras", Revista de Derecho Social núm. 79, 2017, pp. 63-92.

${ }^{13}$ Aunque no se concreta el número de actos intrusivos que pueden dar lugar al tipo penal, el continuum de acciones debe proyectarse en un doble aspecto: a) repetitivo en el momento en que se inicia y b) reiterativo en el tiempo, al repetirse en diversas secuencias en tiempos distintos. Vid., STC sala penal, de 12 de julio de 2017 (Rec. 1745/2016).
} 
14.1 LPRL) alcanza a la protección frente el acoso. En este sentido, el empresario deberá garantizar la seguridad y salud de sus trabajadores en todos los aspectos relacionados con el trabajo y realizará la prevención de riesgos laborales mediante la adopción de cuantas medidas sean necesarias al objeto de cumplir con sus obligaciones de protección (art. 14.2 LPRL). Como riesgos psicosociales relacionados con el trabajo que son la violencia y el acoso en el ámbito laboral, estas actuaciones pueden conllevar un recargo de prestaciones de Seguridad Social por falta de medidas de seguridad y salud en el trabajo (STC 4 de marzo de 2014, Rec. 788/2013).

Puede apreciarse que la normativa laboral, en punto a la tipología y clasificación de la violencia y acoso en el trabajo es, cuanto menos, un poco caótica, y se encuentra dispersa en diversas normas $^{14}$. Además, es relevante señalar que no contamos en el ámbito laboral con una definición legal de acoso moral, aunque este hecho no ha sido óbice para que se haya ido elaborando un concepto jurisprudencial de acoso moral o mobbing, y para que se hayan ido construyendo los elementos objetivos y subjetivos de esta figura a partir de la doctrina judicial (Vid., infra apartado 5).

A salvo de la normativa recogida en el Derecho Penal, principalmente el acoso sexual previsto desde 1995 -aunque reformado con posterioridad-, la regulación de la violencia y el acoso en el ámbito laboral es fruto de una construcción por aluvión, por impulsos o por la necesidad de ir incorporando normativa comunitaria ${ }^{15}$ o, lo que es peor, por modas, sin convicción. Quizás cierta dispersión normativa podría justificarse únicamente en torno a la protección de la denominada violencia de género que, por su singularidad, requiere de un tratamiento específico, integral y diferente, lo que justificaría en parte esta falta de sistematización normativa ${ }^{16}$. Quizás también haya llegado el momento de abrirse a nuevos planteamientos o concepciones (Vid., apartado 7).

\subsection{Las estrictas definiciones del acuerdo marco europeo sobre acoso y violencia en el trabajo de 2007}

En virtud de lo dispuesto en el art. 139 TCE (actual art. 155 TFUE), y tras 10 meses de negociaciones, los interlocutores sociales europeos alcanzaron un acuerdo marco sobre violencia y acoso en el trabajo el 26 de abril de 2007. En el ámbito del diálogo social europeo se adoptó también un acuerdo multisectorial sobre violencia y el acoso de terceros relacionados con el trabajo, suscrito en 2011 por diversos interlocutores sociales europeos.

Con respecto al acuerdo marco europeo de 2007, aunque en su punto 1 se hace referencia a formas muy generales de acoso y violencia en el trabajo, el punto 3, contiene unas definiciones muy estrictas de lo que ha de entenderse por acoso y por violencia, que se tratan como dos realidades distintas: 1.- "se da acoso cuando se maltrata a uno o más trabajadores o directivos varias veces y deliberadamente, se les amenaza, se les humilla en situaciones vinculadas al trabajo"; 2- se habla de violencia cuando se produce la agresión de uno o más trabajadores o directivos en situaciones vinculadas al trabajo. En este mismo punto 3 (párrafos primero, tercero y cuarto), también se hace referencia de forma conjunta al acoso y a la violencia, considerando que son la expresión de comportamientos inaceptables adoptados por una o más personas, y pueden tomar muy diversas

\footnotetext{
${ }^{14}$ Es fragmentaria, lo que genera lagunas y peca de principialista, LOUSADA AROCHENA, F., "El Convenio 190 de la Organización Internacional del Trabajo"; Revista de Derecho Social no 88, 2020, p. 73.

${ }^{15}$ En cuanto a la discriminación por razón de sexo se han promulgado dos Directivas: la 2002/73 que modifica la Directiva 76/207/CEE relativa a la aplicación del principio de igualdad de trato entre hombres y mujeres en lo que se refiere al acceso a la formación y a la promoción profesionales, y a las condiciones de trabajo y la Directiva 2006/54/CE de refundición de la normativa comunitaria relativa al principio de igualdad de oportunidades e igualdad de trato entre hombres y mujeres en asuntos de empleo y ocupación. Véase ALTÉS TÁRREGA, J., El acoso del trabajador en la empresa, Ed. Tirant Lo Blanch, 2008, Valencia, pp. 14-25.

${ }^{16}$ PÉREZ DEL RIO, T., "La violencia de género en el empleo como violación del derecho a la integridad física y psíquica y su prevención. La función de los interlocutores sociales”, Lan Harremanak/ 25, 2012, p. 145.
} 
formas, algunas más fácilmente identificables que otras. La exposición de las personas al acoso y a la violencia puede depender del entorno de trabajo, "con la finalidad o el efecto de perjudicar la dignidad de la víctima, dañar su salud o crearle un entorno de trabajo hostil”.

La poca amplitud de las definiciones que se contienen en este acuerdo marco europeo de 2007 se aprecia, principalmente, en que se gradúan los comportamientos, mayor gravedad en el caso de la agresión, menor en el caso del acoso, lo cual es discutible. Se exige, además, una reiteración en el acoso para ser considerado como tal y, en ambos casos, violencia y acoso, ha de estar presente la intencionalidad o finalidad de causar un daño; aspectos que requieren reflexión. Ello no obstante, es positivo que el acuerdo marco persiga objetivos realistas: "aumentar la sensibilización frente a los supuestos de violencia y acoso, aconsejar la formación para empleados para que disminuyan las probabilidades de violencia y acoso, así como sugerir a las empresas para que declaren la no tolerancia y establezcan procedimientos a seguir en caso de incidentes" (apartado 4, primer párrafo).

\subsection{Las Resoluciones del Parlamento Europeo de 2017 y 2018}

Ante la inactividad normativa de la Comisión Europea, y del Parlamento Europeo como colegislador en los procesos ordinarios, en punto a la violencia y acoso en el trabajo, una vez adoptada la Directiva 2012/29 sobre los derechos de las víctimas de todo tipo de delitos, incluidos los de violencia por motivos de género ${ }^{17}$, han de destacarse por su relevancia dos Resoluciones del Parlamento Europeo: la de 26 de octubre de 2017 sobre la lucha contra el acoso y los abusos sexuales (2017/2897 RSP) y la de 11 de noviembre de 2018 que propone medidas para prevenir el acoso sexual y psicológico en el lugar de trabajo, espacios públicos y en la vida política de la Unión (2018/2055 INI).

En esta última Resolución de 2018, el Parlamento Europeo señala que es consciente de que la violencia en el mundo laboral se aborda de forma fragmentada, con estrategias centradas principalmente en sus formas más visibles, como la violencia física. Sin embargo, el acoso sexual y psicológico puede tener efectos aún más destructivos que la violencia física para la persona afectada (punto 0 ). Es determinante hacer frente a la realidad: un gran número de casos de acoso no se denuncian por vergüenza, por miedo al despido, por incapacidad para conseguir pruebas, por la normalización de las conductas, etc. (punto I).

Entre las medidas que propone el Parlamento Europeo, destacan las siguientes:

1. La Comisión y los Estados miembros, con la participación de los interlocutores sociales y la colaboración de Eurostat y EIGE (Instituto Europeo de Igualdad de Género), deben mejorar, promover y garantizar una recopilación sistemática de datos pertinentes y comparables sobre los casos de acoso sexual y discriminación por razón de género y de acoso psicológico, incluido el ciberacoso.

2. Ha de otorgarse una mayor prioridad a la sensibilización en todos los ámbitos, incluido el de los centros de enseńanza secundaria y universidades, y acoger iniciativas como el movimiento "MeToo" (puntos 12 y 53).

\footnotetext{
${ }^{17}$ La Directiva 2012/29 menciona en su Preámbulo (punto 17) la violencia por motivos de género, con amplitud, en los términos siguientes: "violencia dirigida contra una persona a causa de su sexo, identidad o expresión de género, o que afecte a personas de un sexo en particular de modo desproporcionado se entiende como violencia por motivos de género. Puede causar a las víctimas lesiones corporales o sexuales, dańos emocionales o psicológicos, o perjuicios económicos". "La violencia por motivos de género se entiende como una forma de violación de las libertades fundamentales de la víctima y comprende, sin limitarse a ella, la violencia en las relaciones personales, la violencia sexual (incluida la violación, la agresión sexual y el acoso sexual)... las mujeres víctimas de la violencia por motivos de género y sus hijos requieren con frecuencia de especial apoyo y protección de debido al elevado riesgo de victimización secundaria o reiterada, o de intimidación o represalias ligadas a este tipo de violencia”.
} 
3. El Parlamento Europeo considera obsoleta la definición de acoso sexual contenida en la Directiva $2002 / 73^{18}$ y propone que ésta se modifique "a la luz del devenir de la sociedad, las tecnologías y las costumbres, que han evolucionado y cambiado con el paso del tiempo". Propone que se presente una definición exhaustiva y actualizada de acoso (sexual o de otro tipo) y de acoso laboral. (puntos C y D de la Resolución PE).

4. La Comisión, reitera el Parlamento Europeo, debe presentar una propuesta de Directiva que aborde todas las formas de violencia contra las mujeres y las niñas y de violencia de género, que debe incluir definiciones comunes de las distintas modalidades de violencia contra las mujeres, de acoso sexual o no y de acoso laboral, y unas normas comunes en materia de tipificación de la violencia contra las mujeres como delito (punto 15).

5. El Parlamento considera fundamental para combatir la violencia contra las mujeres que se garantice la igualdad de retribución entre mujeres y hombres como medio para evitar los abusos de poder y promover la igualdad de género y el respeto a la dignidad del ser humano (punto 35)

\section{Las definiciones de violencia y acoso en el trabajo en el Convenio OIT 190}

La OIT ha tomado la delantera a la UE con respecto al tratamiento normativo de la violencia y acoso en el mundo del trabajo, al adoptar por vez primera un instrumento vinculante de carácter internacional que trata la violencia y acoso en el trabajo de forma global e integral. Uno de los principales logros del nuevo Convenio $\mathrm{n}^{\circ} 190$ ha sido precisamente el haber logrado obtener el consenso de todos los Estados y sus interlocutores sociales en torno a la definición de violencia y acoso en el mundo del trabajo.

\subsection{La violencia y el acoso general: un concepto único y minimo}

El Convenio OIT establece (art. 1.1.a) un concepto único sobre violencia y acoso general en el trabajo, que apunta como subgénero a la violencia y acoso por razón de género que, a su vez, incluye al acoso sexual (art.1.1.b). Expresamente el art. 1.1 a señala que la expresión violencia y acoso en el mundo del trabajo "designa un conjunto de comportamientos y prácticas inaceptables, o de amenazas de tales comportamientos o prácticas, ya sea que se manifiesten de una sola vez o de manera repetida, que tengan por objeto, que causen o sean susceptibles de causar, un daño físico, psicológico, sexual o económico, e incluye la violencia y el acoso por razón de género".

El convenio OIT 190 introduce de esta manera un nuevo concepto de violencia y acoso en el trabajo que puede denominarse general. Se habla en la definición establecida en el artículo 1.1.a de comportamientos que causan o pueden causar un resultado: un daño físico, psicológico, sexual o económico. Se trata de un concepto mínimo de referencia ${ }^{19}$, si bien, como señala el propio convenio, nada impide que "la violencia y el acoso puedan definirse en la legislación nacional como un concepto único o como conceptos separados" (art. 1.2 Convenio). Puede apreciarse que lo determinante es que se dé un elemento objetivo, causar dańo o que sea posible causarlo y, en menor

\footnotetext{
${ }^{18}$ Esta Directiva define el acoso sexual como "la situación en que se produce cualquier comportamiento verbal, no verbal o físico no deseado de índole sexual con el propósito o el efecto de atentar contra la dignidad de una persona en particular cuando se crea un entorno intimidatorio, hostil, degradante, humillante u ofensivo" (art. 2.2).

19 VELÁZQUEZ FERNÁNDEZ, M. P., "El Convenio 190 de la OIT sobre violencia y acoso en el trabajo: principales novedades y expectativas", Revista de Trabajo y Seguridad Social, CEF 437-438 (agosto-septiembre 2018), p. 124.
} 
medida, de un elemento subjetivo, que se pruebe que el sujeto o sujetos que lo causen, o pretendan causarlo, tienen intención de causar ese daño o destruir a la víctima (intencionalidad). Se da la intencionalidad pues se dice expresamente "que tengan por objeto"; que los comportamientos o actuaciones tengan por objeto causar un daño. Sin embargo, a la vista del contenido del Convenio, y de lo dispuesto en la Recomendación que lo acompaña, puede apreciarse que lo determinante va a ser el daño causado o la posibilidad de que se cause lo que lleva a enlazar la violencia y acoso en el trabajo directamente con la protección de la seguridad y salud en el trabajo. Por lo demás, puede observarse que el art. 1.1.a del Convenio establece expresamente que no se exige el elemento reiteración; es decir, la expresión "ya sea que se manifiesten de una sola vez o de manera repetida” es clara en cuanto a la exigencia de este elemento de tipificación.

\subsubsection{Prevalencia del elemento objetivo}

A diferencia de las definiciones contenidas en nuestras normas internas, en la norma internacional no se menciona que estas conductas tengan que tener el propósito o efecto de atentar contra la dignidad de la persona, ni tampoco se menciona que la violencia y el acoso deban fundarse en causas discriminatorias para ser consideradas como tales. Pienso que el Convenio se centra especialmente en la producción de un daño, o en la posibilidad de causarlo (daño físico, psicológico, sexual o económico), como elemento objetivo. El concepto violencia y acoso en la norma OIT, se apoya en el resultado final, que se haya producido un dańo o se haya producido la posibilidad de causarlo, más que en determinar que ese posible daño traiga causa o esté causado por un comportamiento intencionado, con la intención de causar esos daños que se mencionan.

\subsubsection{Ausencia del elemento reiteración}

En el art. 1.1 a del Convenio se establece claramente que los comportamientos inaceptables o las amenazas "ya se manifiesten una sola vez o de manera repetida" son constitutivas de violencia o acoso, echando por tierra cualquier exigencia de reiteración en cuanto a la calificación del tipo. Es decir, si llega a ratificarse el Convenio OIT 190, no deberá requerirse la presencia del elemento reiteración, como venía siendo habitual en la doctrina judicial espańola hasta la STC 56/2019. La argumentación jurídica de esta sentencia supone un giro muy importante en cuanto a la concepción judicial del acoso moral, apartándose de la tradicional posición mayoritaria tanto judicial como científica, pues el TC va a entender que ni la intencionalidad de infligir una violencia extrema, ni la constatación de un daño, son elementos necesarios para identificar el tipo jurídico de acoso moral (Vid., Infra apartado 5).

\subsection{La violencia y acoso por razón de género y el acoso sexual}

El Convenio 190 OIT subsume la violencia y acoso por razón de género en el concepto de violencia y acoso general. En este sentido el ya comentando art.1.1.a: "la expresión de violencia y acoso en el mundo del trabajo designa un conjunto de comportamientos o prácticas... e incluye la violencia o acoso por razón de género". Así, en la letra de la norma, la violencia y acoso por razón de género se prevén como un subtipo o subgénero de la violencia y acoso general. A su vez, la norma internacional considera que el acoso sexual es una subespecie de violencia y acoso por razón de género. En este sen- 
tido, el art. 1.1.b del Convenio define la violencia y acoso por razón de género como aquellos "que van dirigidos contra personas por razón de su sexo o género, o que afectan de manera desproporcionada a personas de un sexo o género determinado, e incluye el acoso sexual'. No puede deducirse de lo dispuesto en el Convenio OIT 190, que exista una distinción entre la violencia y el acoso discriminatorio y el que no lo es, doctrinalmente denominado acoso moral, sino que, siguiendo este razonamiento, la tipología general violencia y acoso (art. 1.1 a) contiene como subtipo la violencia y acoso por razón de género (art.1.1.b). Ya se señaló que la principal definición legislativa de acoso discriminatorio en nuestra dispersa normativa, que se recoge en el art. 28.1 de la Ley 62/2003 ${ }^{20}$, procede de la obligación de incorporar el contenido de las Directivas 2000/43 y 2000/78.

\section{La violencia y el acoso como riesgos psicosociales que afectan a la dignidad de las personas}

Un análisis de la definición de acoso y violencia establecida en el art. 1.1.a del Convenio no estaría completo sin una lectura detenida del contenido del mismo y de la Recomendación que lo acompaña. En concreto, desde la propia Exposición de motivos del Convenio hasta el último párrafo de la Recomendación, son numerosísimas las indicaciones que se muestran sobre la intención primaria de la normativa y las razones prioritarias que justifican su adopción: eliminar la violencia y el acoso porque "pueden constituir una violación o un abuso de los derechos humanos...y son inaceptables e incompatible con el trabajo decente" (párrafo 7º Exposición de motivos Convenio); "afectan a la salud psicológica, física y sexual de las personas, a su dignidad, y a su entorno familiar y social" (párrafo 9 Exposición de motivos Convenio); "son incompatibles con la promoción de empresas sostenibles" (párrafo 12).

En este sentido, según el Convenio OIT 190, todo Miembro deberá respetar, promover y llevar a efecto los principios y derechos fundamentales en el trabajo, a saber, ... el trabajo decente y seguro" (art. 5); todo Miembro deberá adoptar una legislación que exija a los empleadores... "tener en cuenta la violencia y acoso, así como los riesgos psicosociales asociados, en la gestión de la seguridad y salud en el trabajo" (art. 9.b) e "identificar los peligros y evaluar los riesgos de violencia y acoso, con participación de los trabajadores y sus representantes, y adoptar medidas para prevenir y controlar dichos peligros y riesgos" (art. 9.c); todo Miembro deberá adoptar medidas apropiadas para... garantizar que todo trabajador tenga el derecho a alejarse de una situación de trabajo ... si tiene motivos razonables para considerar que ésta presenta un peligro grave e inminente para su vida, su salud o su seguridad a consecuencia de actos de violencia o acoso" (art. 10.g); todo miembro debe de esforzarse por garantizar que.. la violencia y el acoso en el mundo del trabajo se aborden en las políticas nacionales pertinentes, como las relativas a la seguridad y salud en el trabajo, la igualdad y la no discriminación y la migración" (art. 11.a).

En cuanto a la Recomendación OIT 206 destacan principalmente los siguientes apartados: apartado 8: "En la evaluación de riesgos en el trabajo... se deberían tener en cuenta los factores que aumentan las probabilidades de violencia y acoso, incluyendo los peligros y riesgos psicosociales. Debería prestarse especial atención a los peligros y riesgos que a) se deriven de las condiciones y modalidades de trabajo, la organización del trabajo y la gestión de los recursos humanos; b) impliquen a terceros como clientes, proveedores de servicios, usuarios, pacientes y el públicos; y c) se deriven

${ }^{20}$ Art. 28.1 de la Ley 62/2003 define el acoso como "toda conducta no deseada, relacionada con el origen racial o étnico, la religión o convicciones, la discapacidad, la edad, la orientación sexual de una persona, que tenga como objetivo o consecuencia atentar contra su dignidad y crear un entorno intimidatorio, humillante u ofensivo". Además, según el apartado 2, último párrafo de este artículo 28, "El acoso por razón de origen racial o étnico, religioso o convicciones, discapacidad, edad u orientación sexual se consideran en todo caso discriminatorio". 
de la discriminación, el abuso de las relaciones de poder y las normas de género, culturales y sociales que fomentan la violencia y el acoso"; y el apartado 23.g, ya mencionado: "Los Miembros deberán financiar, elaborar, aplicar y difundir... campañas públicas destinadas a fomentar lugares de trabajo seguros, salubres, armoniosos y libres de violencia y acoso".

Que la violencia y el acoso en el trabajo tal y como se establecen en la norma internacional sean considerados como riesgos psicosociales tiene desde luego una gran importancia: Primero porque supone reforzar la idea de la prevalencia del elemento objetivo, causar un daño. Segundo porque, en consecuencia, resta peso a la necesidad de tener que probar una intencionalidad lesiva o intención de causar dańo, incluso una intención o finalidad discriminatoria. Ello es muy relevante, pues ha venido siendo doctrina reiterada del TC, en cuanto a la vulneración de derechos fundamentales como, por ejemplo, la prohibición de discriminación por razón de sexo (art. $14 \mathrm{CE}$ ). Como recuerda la STC 108/2019 de 30 de septiembre 2019, (FJ 4), citando la STC 2/2017 de 16 de enero, FJ 6) "puede declararse la lesión de un derecho fundamental aunque no haya ánimo lesivo"; "lo único relevante es que el contenido esencial haya resultado o no menoscabado".

Por otro lado, no es fácil ligar la protección de la seguridad y salud con la violencia y acoso en el trabajo a los efectos de obtener una tutela extraordinaria porque no son derechos fundamentales en nuestra Constitución. Sí lo son la dignidad (art. $10 \mathrm{CE}$ ), la integridad física y moral, la protección frente a trato degradante (art. $15 \mathrm{CE}$ ). Quizás por esta razón y también por imposición de las Directivas comunitarias, los asuntos sobre violencia y acoso en el trabajo se han canalizado tradicionalmente por la vía laboral de la mano del acoso discriminatorio. Avanzar hacia el reconocimiento y tutela de la violencia y el acoso como riesgos psicosociales ${ }^{21} y$, en especial, como conductas o comportamientos que atentan a la dignidad de las personas es, sin duda, un reto pendiente.

\section{Distinción entre el acoso moral y el acoso discriminatorio?}

La mayoría de los autores que han estudiado el fenómeno de la violencia y el acoso en el trabajo han recogido la siguiente distinción ${ }^{22}$ :

1. Por un lado, el acoso moral, mobbing ${ }^{23}$ o presión laboral tendenciosa ${ }^{24}$, que, a pesar de no contar con una definición explícita, ha constituido más del 90 por 100 de las sentencias frente a las que versan sobre acoso discriminatorio ${ }^{25}$. Se ha optado por el concepto acoso

${ }^{21}$ Vid., por todos, NEFFA, J.C., Los riesgos psicosociales en el trabajo: contribución a su estudio, Ed. Centro de Estudios e Investigaciones Laborales CEIL-CONICET; Facultad de Ciencias Económicas de la Universidad Nacional de Nordeste de Argentina, entre otros; 2015; BALLESTER PASTOR, M. A., "La política de la OIT...”, op. cit.; GARCÍA JIMÉNEZ, M., "Violencia externa en el lugar de trabajo: marco conceptual y caracterización jurídica”, Revista Internacional comparada de Relaciones Laborales y Derecho del Empleo, ADAPT University Press, volumen 7, no 2 abril-junio 2019; PÉREZ DEL RIO, T., "La violencia de género...", op., cit.

${ }^{22}$ URRUTIKOETXEA BARRUTIA, M., Acoso laboral y lesión de Derechos fundamentales, ed. Bomarzo, 2014, p. 214; ALTÉS TÁRREGA, J., El acoso del trabajador...”, op. cit., pp. 11-12; BALLESTER PASTOR, M.A., establece una distinción entre acoso psicológico, acoso causal (ligado a cusas concretas de discriminación) y acoso sexual. Vid., Guía sobre el acoso moral en el trabajo, Guías de Negociación, Consejo Andaluz de Relaciones Laborales, 2006, edición actualizada a la Ley Orgánica 3/2007, pp. 11, 14 y 17 ; entre otros.

${ }^{23}$ OLMEDO, M., y GÓNZALEZ, P., "La violencia en el ámbito laboral: la problemática conceptualización del mobbing, su evaluación, prevención y tratamiento", Acción Psicológica, junio 2006, vol. 4, no 2, p. 109.

${ }^{24}$ MEJÍAS GARCÍA, A., "Presión laboral tendenciosa. Medios de protección", en El acoso laboral, antes llamado mobbing, Tirant Monografías no 543, Tirant Lo Blanch, Valencia, 2008, p. 171.

${ }^{25}$ VELÁZQUEZ FERNÁNDEZ, M., "El convenio 190 de la OIT..”, op. cit., p. 129. Cfr. Datos del Observatorio Vasco sobre Acoso y Discriminación. Estudios de la doctrina judicial en materia de acoso en el trabajo, Tirant Lo Blanch, 2019. Sobre el crecimiento espectacular de las demandas por mobbing., Cft. MOLINA NAVARRETE, C., "Del acoso moral (mobbing) al ciberacoso...", op. cit., p. 144. 
moral, frente al de acoso psicológico, pues una violencia de tipo moral daña siempre la dignidad y la integridad de la persona, pero no necesariamente produce un daño psicológico.

2. Por otro lado, el acoso discriminatorio, que incluiría el acoso por razón de género y acoso por cualquier otro motivo (origen racial o étnico, la religión o convicciones, la discapacidad, la edad, la orientación sexual de una persona y otros) y el acoso sexual, como manifestación más grave de discriminación.

Lo dispuesto en los arts. 1.1.a y 1.1.b del Convenio OIT 190, que prevén un concepto de violencia y acoso general, y otro de acoso o violencia de género en el que se subsume el acoso sexual, nos lleva a plantearnos hasta que punto siguen siendo válidas las distinciones doctrinales en torno al acoso moral, por un lado, y discriminatorio, por otro. Que el Convenio OIT 190 no haya recogido esta distinción desde el punto de vista conceptual ha de recibirse de forma positiva pues significa que se está situando al mismo nivel la violencia y acoso que causa daño físico y el que causa daño psicológico, que se viene considerándose acoso moral o mobbing, y esto es muy significativo pues es necesario que este tipo de violencia psicológica o moral se visibilice, para que su protección y tutela se generalice y se trate de forma unificada. Como seńaló el Parlamento Europeo en su Resolución de 11 de noviembre de 2018 (Vid., Supra, apartado 2.3), la violencia en el mundo laboral "se aborda con estrategias centradas principalmente en sus formas más visibles, como la violencia física...sin embargo, el acoso sexual y el psicológico pueden tener efectos aún más destructivos para la persona acosada" (punto $\mathrm{O}$ ).

Bien es cierto que los Estados miembros de la UE están obligados a incorporar el concepto de acoso discriminatorio previsto en las Directivas 2000/43 y 2000/78. Ahora bien, desde el punto de vista conceptual y de cara a validar tipologías, pienso que quizás debería superarse esta distinción (acoso discriminatorio versus acoso moral) pues, tal y como dispone la nueva normativa OIT, el acoso y la violencia en el trabajo pueden ser tratados de forma global e integral, destacándose la mayor relevancia del resultado que estas conductas pueden ocasionar, distinguiéndose a partir de ahí el tipo de daño que se causa: físico, psicológico, sexual o económico. Ello no quiere decir que no haya que prestar especial atención a determinados colectivos más vulnerables o susceptibles de mayor vulnerabilidad, frente a situaciones de violencia y acoso en el ámbito laboral. Pero, de cara a futuro, siempre dependiendo de la evolución de los sistemas jurídicos y según realidades y entornos en los que se sitúen estos comportamientos susceptibles de fiscalización, habrá que dotar a unos colectivos y no a otros de una mayor protección (discriminación por razón de raza, nacionalidad, discapacidad, etc.). El Convenio 190 OIT no olvida a las "personas pertenecientes a uno o varios grupos vulnerables o grupos en situación de vulnerabilidad" y obliga, en este sentido, a todos los Estados que lo ratifiquen a adoptar normas que garanticen el derecho a la igualdad y a la no discriminación (art. 6).

\section{El acoso moral en la doctrina y jurisprudencia española}

En la normativa española no existe un concepto legal de acoso moral, que suele identificarse con algunas conductas típicas, aunque no existe total acuerdo entre psicólogos a la hora de clasificar estas conductas hostiles. Entre esas conductas típicas del acoso moral destacan las siguientes: a) atentados contra las condiciones de trabajo, retirando la autonomía de la víctima y que tienen por objeto desprestigiar y desacreditar su capacidad profesional y laboral (asignarle tareas por debajo de su capacidad, criticar al más mínimo error o defecto, no transmitir información útil, presionarle para que no haga valer sus derechos, etc..); b) limitar su comunicación y contacto social; c) atentados contra su dignidad: observaciones despectivas, se hacen circular rumores y críticas, se le atribuyen problemas 
psicológicos, se le ridiculiza, imita o caricaturiza, se critica su vida privada; d) ataques directos a su salud: se le asignan trabajos u horarios que puedan repercutir negativamente en su salud, no se respetan sus bajas médicas; y e) impedir su promoción e intentar su despido laboral ${ }^{26}$.

La jurisprudencia española ha ido delimitando el concepto de acoso moral distinguiendo entre éste y lo que son tensiones ordinarias que subyacen en toda comunidad de personas. Puede apreciarse una tendencia a la concepción restrictiva del acoso moral, salvo escasas excepciones, con carácter anterior a la STC 56/2019 y un giro importante en la configuración del acoso moral a partir de dicha sentencia.

\subsection{Concepción restrictiva del acoso moral en la jurisprudencia española: la situación anterior a la STC $56 / 2019$}

En esta línea restrictiva, señalaba la STC 81/2018, que el acoso laboral exige "la concurrencia de determinados elementos objetivos y subjetivos, como lo son el hostigamiento continuado y sistemático sobre el empleado, la falta de tutela por quien ostenta el poder de dirección o jerárquico, la gravedad en la conducta empleada, la intencionalidad denigratoria del acosador y el carácter individualizado del destinatario" (FJ 4). Se exige además "una conducta de persecución u hostigamientos sistemático y planificado" (FJ 4). En términos similares, se definía el acoso moral "como el sometimiento sin reposo a pequeños ataques repetidos o también, desde el punto de vista laboral, como una degradación deliberada de las condiciones de trabajo. Que debe tener siempre unos perfiles objetivos como son los de sistematicidad, reiteración y frecuencia y otros subjetivos como lo son la intencionalidad y la persecución de un fin ${ }^{27}$.

No se puede estar de acuerdo con esta concepción tan restrictiva del acoso moral que exige el cumplimiento, y la prueba, de estos elementos. Se olvida la jurisprudencia de que precisamente la violencia y el acoso psicológico es el que no se ve, el que permite actuar sin ser visto y sin dejar huella, y el que es muy difícil probar. Así, frente a la violencia física, la violencia psicológica es sutil, retorcida, propia de personas tóxicas, que pueden manipular a sus víctimas y conseguir el silencio cómplice de las personas que les rodean, ya sea en el tipo de acoso vertical como en el de tipo horizontal. Debería prestarse especial atención al sujeto activo, el acosador o agresor. La conducta agresora puede ser explícita o implícita, ya que puede producirse tanto mediante acciones (burlas, amenazas, críticas...), como mediante omisiones (aislamiento social y laboral, rechazo, menosprecio...) pues una de las formas mas efectivas del acoso, es hacer el vacío a la víctima.

Son muchas las razones que arrastran al acoso moral en el trabajo, correspondiendo a la ciencia de la psicología el estudio de las personalidades típicas de las víctimas y de sus agresores. En cuanto a los sujetos pasivos o víctimas se ha destacado que pueden clasificarse en tres grupos: 1.- personas brillantes, atractivas y algo seductoras y, por tanto, envidiables y consideradas peligrosas o amenazadoras por el agresor que teme perder protagonismo; 2.- personas vulnerables o depresivas que son el blanco fácil del agresor en el que descargan sus propias frustraciones; 3.- personas eficaces y trabajadoras que ponen en evidencia lo establecido y pretenden imponer reformas, que son vistas por el agresor como un peligro o amenaza de su status actual en la empresa ${ }^{28}$. Las características que definen a los agresores, por otro lado, son la exagerada centralización en sí mismos, la

\footnotetext{
${ }^{26}$ OLMEDO, M., y GONZÁLEZ, P., “La violencia en el ámbito laboral...” op. cit., p. 116.

${ }^{27}$ STSJ Andalucía (Granada) Sala de lo Social de 27 de mayo de 2015 (Rec. 428/2015).

${ }^{28}$ CONESA BALLESTERO, J., y SANAHUJA VIDAL., M., "Acoso moral en el trabajo. Tratamiento jurídico (mobbing)", Actualidad Laboral, $n^{\circ}$ 2, 2002. Cit., por HERRERO MAROTO, S., "El síndrome del boreout y la STC 56/2019 sobre mobbing en la Administración Pública”, Diario La Ley, no 9458, 17 de julio de 2019, p. 6.
} 
falta de interés o de empatía hacía los demás y la necesidad de aprobación y triunfo. Acostumbran a ser personas egocéntricas, intolerantes a las críticas y necesitados de admiración y reconocimiento. Podríamos decir que son personas resentidas, frustradas, envidiosas, celosas o egoístas, teniendo uno, varios o todos estos rasgos en menor medida. Están necesitados de admiración, reconocimiento, protagonismo y lo que quieren es figurar, ascender o aparentar, aun cuando simplemente deseen hacer daño o anular a otra persona. El carácter psicopatológico de los agresores permanecerá oculto, en estado latente, hasta que encuentre grietas en la organización por las que ir filtrando todo su potencial destructivo ${ }^{29}$.

La STSJ Castilla y León (Burgos), de 18 de febrero de 2019 (Rec. 12/2019) (FJ 3) seguía en la misma línea restrictiva de la STC 81/2018 mencionada, señalado que los elementos esenciales del acoso laboral tenían que ser los siguientes:

1. Hostigamiento, persecución o violencia psicológica contra una persona o conjunto de personas. No cabe confundirlo con una mera situación de tensión en el trabajo o mal clima laboral; es necesario que la víctima sea objeto de un conjunto de actuaciones que configuren un panorama de maltrato psíquico o moral, una denigración o vejación del trabajador.

2. Carácter intenso de la violencia psicológica: violencia extrema o intensa... "se requiere que el hostigamiento tenga un alto grado de intensidad. En caso de que no concurra tal intensidad y la persona resulte afectada, la patología tendría que ver más con la propia personalidad de afectado que con la real hostilidad del entorno laboral".

3. Prologada en el tiempo: significa que no basta con que la violencia se manifieste como un mero episodio aislado, se produzca en un momento concreto o de forma esporádica.

4. Que tenga como finalidad dañar psíquica o moralmente al trabajador, para marginarlo de su entorno laboral: elemento que sirve de nexo o conductor (intencionalidad); "hay que tener en cuenta que la intencionalidad puede ser un elemento plenamente consciente o premeditado o puede existir de forma larvada, formas de rechazo y hostilidad hacia la víctima, el propio acosador puede no racionalizar conscientemente, pero que pueden manifestar de forma más o menos subconsciente la intencionalidad oculta de su entorno de trabajo".

5. Existe un quinto elemento, respecto de cuya exigencia discrepan los autores y la jurisprudencia al construir el concepto de acoso: si es exigible o no que se produzcan daños psíquicos en el trabajador afectado.

En sentido similar, una amplia doctrina de suplicación señalaba los elementos fundamentales del acoso moral o mobbing y muchísimas sentencias, la mayoría de ellas, desestiman recursos de suplicación por considerar que no existe acoso moral ${ }^{30}$. Ello es seguramente consecuencia de acogerse a la existencia de los estrictos elementos señalados para configurarse el tipo de la violencia y acoso psicológico. Pero, sobre todo, la ausencia de estimaciones en la vía judicial se debe directamente a la gran dificultad que supone para las víctimas tener que probar los hechos y comportamientos lesivos. Así, por ejemplo, la STSJ Castilla-La Mancha (Albacete) de 25 de abril de 2019 (Rec. 440/2018), desestima el recurso de suplicación entendiendo que no existe acoso moral porque no se dan "determinados componentes objetivos (presión continuada, relación de causalidad con el trabajo, falta de amparo en el poder de dirección y gravedad en la conducta empleada) y subjetivos (intencionalidad denigratoria y carácter individualizado -que no colectivo- del destinatario)" (FJ 1).

${ }^{29}$ CORREA CARraSCO, M., Acoso Laboral. Regulación jurídica y práctica aplicativa, Colección laboral no 258, Tirant Lo Blanch, Valencia, 2019, p. 10.

${ }^{30}$ MOLINA NAVARRETE, C., "La < des-psicologización> del concepto constitucional del acoso moral en el trabajo: ni la intención ni el daño son elementos del tipo jurídico”, Revista de Derecho Social no 86, abril-junio 2019, pp. 127-140. 
En términos un poco mas suaves se pronunció la STSJ Andalucía (Sevilla) de 4 de abril de 2019 (Rec. 1012/2018) (FJ 4), que hace hincapié en que "lo relevante no es el concepto de acoso moral sino los elementos, distinguiendo con claridad: a) los elementos esenciales o estructurales del tipo que si no concurren la conducta no puede calificarse de acoso moral: elemento cronológico, reiteración, elemento medial y la complejidad de la conducta; y b) los elementos accidentales o contingentes, que pueden estar presentes o no: elemento finalista o subjetivo, voluntad de destruir la personalidad, y también el resultado, el daño físico. En esta sentencia, el TSJ Andalucía (Sevilla) señala que "corresponde a la trabajadora acreditar tanto el elemento cronológico, la reiteración de conductas, y el elemento medial, la complejidad de la conducta, es decir, acreditar los hechos que a su juicio comportan la intimidación psicológica denunciada, tales como el aislamiento, la desocupación, los insultos, las humillaciones, la no asignación de tareas, la asignación de funciones sin contenido real o práctico etc...conductas que de no probarse es imposible afirmar que se fue sujeto pasivo de un acoso". Para concluir que efectivamente (por falta de prueba) "lo que la actora llama un acoso laboral es en realidad... mera conflictividad derivada de las relaciones laborales”. Como señalara la STSJ Canarias (Las Palmas de Gran Canaria) de 22 de mayo de 2017, (Rec. 467/2017)(FJ 4) "no puede confundirse el mobbing con los conflictos laborales que puedan originarse por defender los sujetos de la relación laboral intereses contrapuestos, ni con el estado de agotamiento provocado por el estrés profesional, ni con manifestaciones de maltrato esporádico o de sometimiento a inadecuadas condiciones de trabajo".

Si puede apreciarse un tímido cambio en la jurisprudencia en torno a la conceptualización del acoso moral en la STSJ Andalucía (Granada) de 18 de julio 2019 (Rec. 13/2019)(FJ 3) que estima, en atención a las definiciones de acoso (discriminatorio) de las Directivas comunitarias (2000/43 y 2000/78), "que no se precisan disquisiciones doctrinales entorno a lo que es o no acoso o sus diversas manifestaciones. La cuestión escriba, por tanto, en determinar si el comportamiento empresarial: 1) tiene como objetivo o consecuencia atentar contra la dignidad; y 2) crear un entorno hostil".

\subsection{La definición judicial del acoso moral a partir de la STC 56/2019}

La STC 56/2019 ha supuesto un antes y un después en cuanto a la concepción judicial del acoso moral en nuestro país. A partir de ella, ni la intencionalidad de infligir una violencia extrema, ni la constatación de un daño, son elementos necesarios para identificar el acoso moral. El asunto del que conoce la STC 56/2019 versa sobre un funcionario que había sido cesado de su puesto, por cambios políticos, y que se reincorporaba a su anterior trabajo, donde tenía reserva de puesto. Allí "se le asigna un puesto de trabajo exclusivamente formal o aparente, sin funciones definidas", "se le mantiene durante largo tiempo sin información", y se "hace caso omiso de sus reiteradas peticiones de tareas o traslación de destino" (FJ 1). Del contenido de la STC 56/2019 destaca lo siguiente:

1. Argumenta el TC (FJ 5, apartado b) que la inactividad laboral a la que fue sometido el trabajador "involucra inequívocamente su derecho fundamental a la integridad moral y a la prohibición de tratos degradantes (art. $15 \mathrm{CE}$ )". "Las intromisiones del poder público en la integridad personal... constituyen un atentando < frontal y radical> a la dignidad humana... por eso están sujetas a una prohibición absoluta... sean cuales fueren los fines (STC 120/1990, FJ 9); es decir, en modo alguno puede ser determinante la mayor o menor bondad o legitimidad de la finalidad pretendida (ATC 333/1997, de 13 de octubre, FJ 5)" (FJ 5 apartado c).

2. Señala el TC que "si faltase el último elemento -el fin de vejar, humillar...- no habrá trato degradante, pero solo podrá descartarse la lesión de la integridad moral si el comporta- 
miento enjuiciado cuenta con cobertura legal -legalidad-, responde a un fin constitucionalmente legítimo -adecuación-, constituye la alternativa menos restrictiva -necesidad-y produce mas beneficios sobre otros bienes o valores que perjuicios en el derecho fundamental (art. 15 CE)" (FJ 6).

3. Habla esta sentencia del "carácter intencional no causal", y que corresponde en su caso "a la parte demandante -en este caso, la administración pública que acosa- la carga de probar que su actuación tuvo causas reales absolutamente extrańas a la pretendida vulneración" (STC 104/2014, FJ 7)" (FJ6).

4. Con respecto a la exigencia de que se cause un daño o perjuicio extremo, la STC 56/2019 aclara que "en la hipótesis de que hubiera faltado el componente vejatorio, el trato dispensado no habría podido considerarse degradante, pero, en ausencia de cobertura legal y de un objetivo legítimo, habría incumplido ad limine el canon de la proporcionalidad, por lo que habría vulnerado igualmente el derecho a la integridad moral del demandante de amparo (art. $15 \mathrm{CE}$ )" (FJ 6). En este sentido, a partir de la doctrina que sienta ahora la SCT 56/2019, no hará falta constatar una violencia o acoso extremos, separándose así de lo que venía exigiéndose por la justicia para determinar la existencia de acoso moral.

\section{Más allá de la violencia y del acoso por razón de género}

A la vista de lo dispuesto en el Convenio 190 de la OIT (art.1.1.a), como se ha señalado, prevalece un concepto único y general de violencia y acoso, que incluye el acoso y violencia por razón de género y el acoso sexual como parte de los mismos. En el Convenio OIT se define la violencia y el acoso por razón de género o sexo en los términos siguientes (art.1.1.b ): "violencia y acoso que van dirigidos contra las personas por razón de su sexo o género, o que afectan de manera desproporcionada a personas de un sexo o género determinado, e incluye el acoso sexual".

\subsection{La reticencia a incorporar referencias a la discriminación por razones de orientación sexual}

Las razones por las cuales no se hace referencia expresa en la norma internacional a la violencia y acoso por razón de discriminación ${ }^{31}$, más allá del reconocimiento de la violencia o acoso por razón de género o sexo, y dentro de éste el del acoso sexual, hay que buscarlas en los antecedentes a la elaboración del Convenio 190 OIT. Algunos países eran totalmente reticentes a incorporar en la norma internacional cualquier referencia a la orientación sexual como motivo de discriminación ${ }^{32}$. Es relevante también que determinadas organizaciones empresariales, por ejemplo la CGECI ${ }^{33}$, se pronunciaría expresamente en favor de "eliminar referencias específicas a las personas lesbianas, gays, bisexuales o transgénero"; mientras que otras patronales, se pronunciaron, por el contrario, en favor de incluir referencias a las personas LGTBI, considerando que éstas también se ven afectadas de forma desproporcionada por la violencia por razón de género ${ }^{34}$.

${ }^{31}$ Tal y como viene entendiéndose por acoso discriminatorio, según la definición establecida en la Directiva 2000/78, acogida en el art. 28.1 de nuestra Ley 62/2003: "toda conducta no deseada, relacionada con el origen racial o étnico, la religión o convicciones, la discapacidad, la edad, la orientación sexual de una persona, que tenga por objeto o consecuencia atentar contra su dignidad y crear un entorno intimidatorio, humillante u ofensivo"

${ }^{32}$ Entre ellos, República Islámica de Irán, Kuwait y Polonia. Informe 2A, p. 19.

${ }^{33}$ Confederación General de Empresas de Côte d'Ivore.

${ }^{34}$ Como la CEOE, CEPYME, NEF (Federación de Empleadores de Namibia), NHO (Confederación de empresas de Noruega); CONFIEP (Confederación de Nacional de Instituciones Privadas de Perú) y VBO-FEB (Federación de Empresas Belgas.) 
El término LGTB, que surgiría en los años 90, ha ido evolucionando -y probablemente lo seguirá haciendo- hacia el actual LGTB+, que incluye a personas lesbianas, gays, bisexuales, transexuales, intersexuales, queer, pansexuales, asexuales y personas que cuestionan su sexualidad. Es significativo resaltar que, hasta el año 2018, la transexualidad era considerada por la Organización Mundial de la Salud (OMS) como una enfermedad mental ${ }^{35}$. El colectivo de las personas transgénero sigue sufriendo en la actualidad un elevado grado de discriminación y de estigmatización social. La protección jurídica efectiva de estas personas no puede limitarse a aquellas que se han sometido a una operación de cambio de sexo, sino que debe desarrollarse una conceptualización de la identidad de género que sea amplia e inclusiva, basándose en el reconocimiento de la autonomía individual y de la dignidad de la persona, y en el respeto a los derechos fundamentales que le son inherentes ${ }^{36}$.

\subsection{Violencia y acoso contra las mujeres}

El Convenio OIT 190 presta especial atención a la violencia y acoso por razón de género con clara referencia a las mujeres. La propia Exposición de motivos del Convenio recuerda que la violencia y el acoso por razón de género "afecta de manera desproporcionada a las mujeres y las niñas" y reconoce la necesidad de la adopción de un enfoque inclusivo e integrador que tenga en cuenta las consideraciones de género, y "que aborde las causas subyacentes y los factores de riesgos, entre ellos los estereotipos de género, las formas múltiples e intersectoriales de discriminación y el abuso de las relaciones de poder por razón de género" (párrafo 13).

\subsubsection{Causas subyacentes y factores de riesgo}

Abordar las causas subyacentes y los factores de riesgo que contribuyen a la mayor incidencia de acoso y violencia en las mujeres es tarea ardua; también lo es poder distinguir lo que son causas, de lo que son factores de riesgo. En la Recomendación 206 OIT que acompaña al Convenio 190 se apuntan, como "factores que aumentan la probabilidad de acoso y violencia en el trabajo" (en general, sin especificar que se trate de la violencia y acoso por razón de género), los siguientes: la discriminación, el abuso de poder y las normas de género, y causas culturales y sociales que fomentan la violencia y el acoso" (apartado 23.a); y los peligros y riesgos psicosociales (apartado 8).

En el trasfondo de la violencia y acoso contra las mujeres se encuentra una relación de poder desigual perpetuado a lo largo de la historia. Ello no obstante, ha de destacarse que las desigualdades entre hombres y mujeres en el ámbito familiar, educativo y social no son suficientes para explicar la discriminación que sufre la mujer en el mundo laboral. El mercado laboral no solo reproduce estas desigualdades, sino que las incentiva y las agrava ${ }^{37}$. La desprotección y la discriminación de la mujer no sólo deriva de su condición de mujer, sino también de las circunstancias del mercado laboral para ellas y la situación de precariedad que padecen como consecuencia de la violencia económica que se viene ejerciendo sobre las mujeres. A su vez, ha de plantearse también hasta que punto sería viable, y aceptable, llevar a cabo una distinción entre mujeres con o sin responsabilidades o cargas familiares, incluyendo entre éstas no solo las tradicionales de maternidad y crianza de hijos, sino todas aquellas inherentes al cuidado del hogar, de los mayores etc. Sin duda, la lucha contra la violencia hacia las mujeres necesita incorporar a los poderes públicos pero también a los hombres en su discurso.

\footnotetext{
${ }^{35}$ Clasificación Internacional de Enfermedades (CIE-11).

${ }^{36}$ DIAZ LAFUENTE, J., "El reconocimiento de la identidad de género por el Tribunal de Justicia de la Unión Europea. Comentario a la STJUE de 26 de junio de 2018, asunto C-451/16", RTSS. CEF, núm. 427, octubre 2018, p. 207.

${ }^{37}$ ESPEJO MEGÍAS, P., Hacia una reformulación de la violencia de género laboral, Madrid, Wolkers/Kluwer/ La Ley, 2018, p. 41.
} 
7.2.2. Medidas para mitigar la violencia contra las mujeres previstas en la Recomendación 206 OIT

La Recomendación 206 OIT establece determinadas medidas para hacer frente a la violencia y acoso por razón de género y también otras dirigidas a mitigar el impacto de la violencia doméstica en el ámbito del trabajo. Que se haya optado por los conceptos habitualmente utilizados -violencia por razón de género y violencia doméstica- en lugar del más genérico y amplio, violencia contra las mujeres, seguramente responde a la necesidad de obtener el consenso de los Miembros de cara a la adopción del Convenio. En cualquier caso, se recogen en la Recomendación, que no es jurídicamente vinculante, interesantes medidas a tener en cuenta por los poderes públicos de los Miembros que ratifiquen el Convenio OIT 190.

En concreto, en cuanto a la violencia y al acoso por razón de género, el apartado 16 de la Recomendación aconseja que los mecanismos de presentación de quejas y de solución de conflictos, "deberían contener", las medidas siguientes: a) tribunales con personal especializado; b) una tramitación diligente y eficiente de los casos; c) asistencia y asesoramiento jurídicos para los denunciantes y para las víctimas; d) guías y otros medios de información disponibles y accesibles en los idiomas de uso corriente del país; y e) la inversión de la carga de la prueba, si procede, en procedimientos distintos de los penales.

El apoyo y las vías de recurso y reparación para las víctimas de violencia y acoso por razón de género "deberían comprender" medidas como: a) apoyo a las víctimas para reincorporarse en el mercado de trabajo; b) servicios accesibles, según proceda, de asesoramiento e información; c) un servicio de atención telefónica disponible las 24 horas; d) servicios de emergencia; e) atención y tratamiento médico y apoyo psicológico; f) centros de crisis, incluidos los centros de acogida; g) unidades especializadas de la policía o de agentes con formación específica para ayudar a las víctimas (apartado 17 de la Recomendación). Muy interesante resulta lo dispuesto en el apartado 20 de la Recomendación 206: "Los inspectores de trabajo y los agentes de otras autoridades competentes, según proceda, deberán recibir formación específica sobre las cuestiones de género para poder detectar y tratar la violencia y el acoso en el mundo del trabajo, incluidos los peligros y riesgos psicosociales, la violencia y el acoso por razón de género y la discriminación ejercida contra determinados grupos de trabajo".

En cuanto a la violencia doméstica y su impacto en el mundo del trabajo, el apartado 17 de la Recomendación establece las siguientes medidas: a) licencia para las víctimas de violencia doméstica; b) modalidades de trabajo flexibles y protección para las víctimas de violencia doméstica; c) protección temporal para las víctimas de violencia doméstica contra el despido, según proceda, salvo que el motivo del mismo no esté relacionado con la violencia doméstica y sus consecuencias; d) la inclusión de la violencia doméstica en la evaluación de riesgos en el lugar de trabajo; e) un sistema de orientación hacia mecanismos públicos de mitigación de la violencia doméstica, cuando existan; y f)la sensibilización sobre los efectos de la violencia doméstica.

7.2.3. Violencia de género y violencia doméstica versus violencia contra las mujeres desde el punto de vista conceptual

Tanto la Recomendación 206 como el Convenio 190 mantienen los conceptos tradicionales "violencia y acoso por razón de género" y "violencia doméstica". En este sentido, con respecto a la violencia y acoso por razón de género pueden verse, el art. 1.1.b del Convenio relativo a su definición ("designa la violencia y el acoso que van dirigidos contra las personas por razón de su sexo o género, o que afectan de manera desproporcionada a personas de un sexo o género determinado, e incluye el acoso sexual"), como los siguientes artículos: el art. 4 del Convenio exige a sus Miembros que 
adopten "un enfoque inclusivo, integrado y que tenga en cuenta las consideraciones de género para prevenir y eliminar la violencia y acoso en el mundo del trabajo"; de nuevo en el art. 7 se establece que los Miembros deben adoptar una legislación que "prohíba la violencia y acoso en el trabajo, con inclusión de la violencia y acoso por razón de género"; también en el art. 10. e, en punto a las medidas apropiadas a adoptar, se refuerza de nuevo la razón "de género", en cuanto a las medidas apropiadas "deberán prever que las víctimas de violencia y acoso por razón de género en el mundo del trabajo tengan acceso efectivo a mecanismos de presentación de quejas y de solución de conflictos, asistencia, servicios y vías de recurso y reparación que tengan en cuenta las consideraciones de género y que sean seguros y eficaces".

Se ha apuntado que, seguramente, para poder obtener el consenso de los Miembros en la adopción de este importante instrumento legal, el primero sobre violencia y acoso en el trabajo de carácter normativo y ámbito internacional, haya sido necesario utilizar denominaciones tradicionales, violencia por razón de género y violencia doméstica, que no arriesgan, aceptados por todos ${ }^{38}$. Pienso que habría que plantearse si es más adecuado utilizar el concepto "violencia y acoso contra las mujeres", pues es muy llamativo hablar en términos de un género indeterminado cuando se está haciendo referencia clara al 50 por 100 de la población mundial. Lo que está claro es que el fenómeno de la violencia y acoso contra las mujeres va más allá del ámbito laboral; es un hecho transversal y universal que se manifiesta o causa todo tipo de daños físicos, psicológicos, sexuales y económicos. Es por ello que también se ha puesto de manifiesto las diferencias terminológicas en torno a los conceptos violencia de género y violencia doméstica ${ }^{39}$; subsumiéndose el segundo (violencia doméstica) en el primero (violencia de género).

Es comúnmente aceptado que hablar de violencia o acoso "por razón de género" es hablar de violencia y acoso contra las mujeres, entendiéndose que ambos conceptos representan una misma realidad. Ahora bien, quizás hablar de "género" sin especificar de que género se trata puede dar a entender que este concepto incluye también a otros colectivos con una orientación sexual distinta a la heterogénea (hombre-mujer); lo que significaría que sería terminológicamente más correcto, entonces, hablar de "orientación sexual" y no de "género". Esto no sería un problema, sino más bien un cambio léxico-semántico; pero entonces este cambio no sería conforme con la letra del Convenio OIT 190, que obvia cualquier referencia a la "orientación sexual", y que se refiere en su articulado, y en la Recomendación 206, a "personas de un sexo o género determinado, e incluye el acoso sexual"... "a los que afecta de manera desproporcionada". Claramente cuando el Convenio OIT habla de violencia o acoso por razón de género se refiere al género o sexo femenino, es decir, a las mujeres.

Sea el Convenio OIT el instrumento adecuado o no para plantearse un cambio en la terminología, que no parece que lo sea, si debería tenerse en cuenta la adecuación de seguir manteniendo el término "violencia de género" cuando en definitiva estamos hablando de "violencia contra las mujeres". Las limitaciones de seguir utilizando el concepto de violencia de género han sido puestas de manifiesto por la doctrina con ocasión del análisis de la LO 1/2004 de protección integral contra la violencia de género, que se limita a tratar la violencia que se ejerce sobre las mujeres por parte de quienes han sido o son cónyuges o han tenido o tienen una relación de afectividad con ellas, quedando excluida la violencia y acoso ejercida sobre las mujeres por cualquier otro hombre ${ }^{40}$. Bien

\footnotetext{
${ }^{38}$ Se ha señalado que no se debe confundir "género" y "mujeres". Género es una categoría de análisis de las relaciones entre hombres y mujeres, como lo es la categoría "clase social" que no se identifica con la clase trabajadora. TAMAYO ACOSTA, J. J., "Principales categorías de la teoría de género" en BLÁZQUEZ AGUADO, E., SAINZ DE BARANDA ANDÚJAR, C. y NIETO ROJAS, P. (Dirs.), Especialista en Gestión de Politicas de Igualdad, Thomson Reuters Aranzadi, Cizur Menor, Navarra, 2019 , p. 96.

${ }^{39}$ YUGUEROS GARCÍA, A. J., "La violencia contra las mujeres: conceptos y causas", Revista Castellano-Manchega de Ciencias Sociales, no 18, 2014, p. 148. ESPEJO MEGÍAS, P., Hacia una reformulación de la violencia de género...” op. cit., p. 58; PÉREZ DEL RIO, T., La violencia de género en el ámbito laboral: el acoso sexual y el acoso sexista, Albacete, Bomarzo 2009, p. 22.

${ }^{40}$ GARCIA TESTAL, R., Derechos de las trabajadoras víctimas de la violencia de género, op. cit., pp. 14-15.
} 
es cierto que el Convenio OIT 190 se dedica a abordar la violencia y el acoso en el mundo laboral, utilizando con buen juicio un concepto único e integral que pretende proteger a todos, con independencia de su género u orientación sexual. También ha de tenerse presente que sus disposiciones $\mathrm{y}$, muy significativamente, los apartados sobre violencia de género y violencia doméstica contenidos en la Recomendación 206 son de gran importancia para aquellos sistemas jurídicos ajenos a cuestiones relativas a la violencia contra las mujeres. Comenzar por introducir cambios, aunque sean simplemente terminológicos, a través del ámbito laboral, es siempre un buen camino.

\subsubsection{La violencia económica contra las mujeres}

Con respecto al ámbito laboral y a la violencia contra las mujeres, hubiera sido interesante encontrar en el Convenio indicaciones en torno a lo que podíamos denominar violencia económica contra las mujeres, en concreto, sobre sus manifestaciones típicas: la discriminación salarial, el llamado "techo de cristal" y la más reciente "barrera de acero".

La discriminación salarial se manifiesta en la percepción por las mujeres de un menor salario por el mismo trabajo o de igual valor que el que realizan los hombres. Sin perjuicio de los numerosos instrumentos internacionales y de la normativa europea, han de destacarse, por un lado, la Directiva 2006/54 que dedica sus arts. 4-13 a la igualdad retributiva entre hombres y mujeres y, por otro, el art. 28 ET que incorporó la norma comunitaria citada, y que contiene nuevos apartados a partir de la reforma operada por el Real-Decreto Ley 6/2019, de 1 de marzo. En concreto, en este artículo 28: 1.- se define cuando un trabajo tiene igual valor que otro (art. 28.1, $2^{\circ}$ párrafo); 2.- se obliga al empresario a llevar un registro medio de los salarios, complementos salariales y percepciones extrasalariales de su plantilla "desagregados por sexo y distribuidos por grupos profesionales, categorías profesionales o puestos de trabajo iguales o de igual valor" (art. 28.2); y 3.- se exige al empresario que incluya en el registro una justificación alegando que las diferencias salariales no responden a motivos relacionados con el sexo de las personas; ello a partir de 2022 en empresas de al menos 50 trabajadores (art. 28.3 ET).

Desgraciadamente, a pesar de la existente normativa a nivel internacional, europeo e interno -y a salvo de esperar los frutos del cambio normativo comentado-, y a pesar de la labor de los tribunales y de los esfuerzos de los interlocutores sociales, y/o de sus pretensiones, no se logra evitar la discriminación retributiva de las mujeres. Según datos de Eurostat (2017) el salario de las mujeres (EU-28) fue un 16 por 100 inferior al de los hombres; España se sitúa en 15,1 por 100 pero es el segundo país -después de Malta- donde más aumentó en ese año, un 0,9 por 100. En el INE pueden verse datos segregados sobre la brecha salarial en España (según tipo de jornada, tipo de contratos, según la edad, sectores de actividad económica, etc.). En este sentido, es llamativo que la brecha salarial en el sector público es de 15,9 por 100 pero alcanza el 19,3 por 100 en el sector privado. Sobre la discriminación salarial y su evolución en el mundo puede verse el Informe global de 2019 del Índice de Instituciones Sociales e Igualdad de Género (SIGI) publicado por la OCDE.

Entre los factores que pueden explicar al menos en parte la brecha salarial figuran los siguientes: la segregación sectorial y profesional, la educación o la formación; las desigualdades existentes en materia de responsabilidades familiares; la prevalencia del trabajo precario, a tiempo parcial o atípico; y las discriminaciones directas o indirectas. Importante ha sido la labor del TJUE en la definición del concepto retribución que inicialmente era mas restrictivo pero que ha ido ampliándose paulatinamente ${ }^{41}$.

\footnotetext{
${ }^{41}$ Un recorrido por la jurisprudencia europea e interna puede verse en RODRÍGUEZ ESCANCIANO, S., "La discriminación retributiva por causa del sexo y género: factores desencadenantes y pautas de solución”, Documentación Laboral, núm. 113-año 2018, Vol. I, pp. 10-22.
} 
El denominado "techo de cristal" hace referencia a la escasa presencia de la mujer en los puestos de mayor nivel en el ámbito de las empresas y en la vida política. Las mujeres continúan siendo responsables del ámbito doméstico por lo que encuentran serias dificultades para implicarse en los niveles de mayor responsabilidad ${ }^{42}$. Se requiere con urgencia seguir en la línea de solucionar los problemas que acarrea la realización de dobles o triples jornadas de trabajo con claro perfil femenino. Entre las posibles medidas a adoptar, las siguientes: ajustes en la organización del trabajo que permitan rebajar los periodos de permanencia física en el lugar de trabajo; mejorar la dotación de red pública de cuidados para abarcar las necesidades existentes (guarderías, centro de día, atención a las personas dependientes, etc.); políticas que fomenten la corresponsabilidad; un sistema fiscal que fomente la independencia económica de las madres; entre otras.

A todo ello hay que sumarle que las mujeres, denominadas colectivo diana, son las principales afectadas ante contextos económicos adversos, caracterizados por la precariedad en el empleo, la inestabilidad, la temporalidad excesiva, la elevada rotación, etc., Cuestiones que afectan directamente a sus condiciones laborales. Además, los salarios inferiores de las mujeres consecuencia de su prevalencia en puestos de trabajo de menor retribución determinan un nivel inferior de cotización a la Seguridad Social que impacta sobre la calidad de sus prestaciones en comparación con las de los hombres ${ }^{43}$. Sobre esta cuestión se ha pronunciado el TJUE en dos ocasiones: 1) en Sentencia de 8 de mayo de 2018, asunto C-161/18 sobre cuestión prejudicial suscitada por el TSJ de Castilla y León (Valladolid) Auto de 17 de enero de 2018 (Rec. 1857/2017) sobre el coeficiente de parcialidad que representa la jornada a tiempo parcial frente a la realizada por un trabajador a tiempo completo; y 2) en Sentencia de 8 de mayo de 2018, asunto C-486/1, sobre un subsidio de recolocación francés reconocido a una personal que presta sus servicios a tiempo parcial. En ambos supuestos el TJUE desvela sendas discriminaciones indirectas por razón de sexo ${ }^{44}$.

Con el término "barrera de acero" se hace referencia a la aparición de una nueva limitación para el avance de las mujeres en las empresas debido a su falta de experiencia internacional. Las mujeres no son asignadas a puestos en el extranjero y, por tanto, tienen menos oportunidades que sus compañeros hombres para optar a puestos de alta dirección en empresas que operan en el ámbito multinacional. La mujer queda relegada de destinos en el extranjero frecuentemente por razones subjetivas y por resistencia organizativa. Se denomina de acero porque esta barrera es más compleja y difícil de romper que el "techo de cristal" 45.

\subsection{El acoso sexual}

El acoso sexual en el Convenio OIT 190 se establece como subgénero de la violencia y acoso de género: "la violencia y acoso por razón de género...incluye el acoso sexual" (art. 1.1.b). Se sigue, en este sentido, la tradicional consideración del acoso sexual y del acoso sexista como manifestaciones de la violencia de género, y como formas más graves de discriminación por razón de sexo. Ello es

${ }^{42}$ Vid., BLÁZQUEZ AGUADO, E., "Una aproximación a la igualdad de género en el mercado laboral” en BLÁZQUEZ AGUADO, E., SAINZ DE BARANDA ANDÚJAR, C. y NIETO ROJAS, P. (Dirs.), Especialista en Gestión de Politicas de Igualdad, op. cit., pp. 273-284. P. 273: "Existe una relación directa entre producción y reproducción. La asunción de cargas familiares por las mujeres reduce sus oportunidades profesionales en el mercado laboral. A mayor preparación, menor número de hijos/as y más atención a su carrera profesional y viceversa".

${ }^{43}$ RODRÍGUEZ ESCANCIANO, S., "La discriminación retributiva...”, op. cit., p. 26.

${ }^{44}$ Vid., MOLINA NAVARRETE, C., "Identidad europea, brechas de género y protección social: el Tribunal de Justicia de la Unión Europea desnuda persistentes discriminaciones por razón de sexo", RTSS, CEF, 435 (junio 2019), pp. 5-12.

${ }^{45}$ BASTIDA DOMÍNGUEZ, M., "Del cristal al acero: nuevas barreras para nuevos tiempos", RTSS.CEF, núm. 429 (diciembre 2018), p. 237. 
así pues, como se recoge en la Resolución del Parlamento Europeo de 2018 (apartado F), el 90 por 100 de las víctimas son mujeres, frente al 10 por 100 de los hombres ${ }^{46}$. La norma internacional no contiene mayores indicaciones en punto al acoso sexual. Figura que ha sido tratada por la doctrina en numerosas ocasiones ${ }^{47}$. Quedaría si acaso por destacar que el número de asuntos que llegan a los Tribunales siguen siendo muy escasos, aunque sí se aprecia una mayor incidencia, o una mayor visibilidad, del acoso sexual en determinados ámbitos como el militar y policial ${ }^{48}$; y también en cuanto a las situaciones de violencia y acoso sexual que están sufriendo las trabajadoras migrantes o inmigrantes ${ }^{49}$.

\section{8. Ámbito de aplicación subjetivo del Convenio 190 OIT}

Uno de los aspectos más llamativos del Convenio OIT 190 es su amplio ámbito de aplicación, tanto desde el punto de vista subjetivo, personas incluidas bajo el amparo de la normativa, como espacial, entendido como lugar de trabajo a efectos de aplicación de las disposiciones contenidas en el Convenio.

\subsection{El trabajador y otras personas relacionadas con el mundo del trabajo}

En punto al ámbito de aplicación subjetivo, el amplio enfoque que ha adoptado el Convenio OT 190 es muy significativo en la medida que van a quedar bajo su protección todas las personas que trabajan y no sólo ellas. En este sentido, el art. 2.1 del Convenio se refiere a los trabajadores asalariados "según se definen en las legislaciones y prácticas nacionales" pero también a las personas que trabajan, "sea cual sea su situación contractual". Entre estos últimos expresamente incluye a las personas en formación, pasantes, aprendices, los trabajadores despedidos, los voluntarios, las personas en busca de empleo y los postulantes a un empleo, y los individuos que ejercen la autoridad, las funciones o la responsabilidad de un empleador.

Muy significativa también es la mención a "terceros" (art. 4.2 Convenio) pues, de forma sutil, se hace referencia a que terceros, ajenos a la relación laboral. Se habla en el Convenio OIT 190 de la necesidad de que los Miembros adopten "un enfoque inclusivo, integrado y que tenga en cuenta las consideraciones de género para prevenir y eliminar la violencia y el acoso en el mundo del trabajo. Este enfoque debería tener en cuenta la violencia y el acoso que impliquen a terceros, cuando

\footnotetext{
${ }^{46}$ Como se señala en el Informa de la FRA (Agencia Europea de Derechos Fundamentales de la UE), Luxemburgo, 2014: una de cada tres mujeres ha sufrido violencia física o sexual durante su vida adulta; que, en la Unión, hasta un 55 por 100 de las mujeres han sido objeto de acoso sexual; que el 32 por 100 de todas las víctimas en la Unión Europea señalaron que el agresor había sido un superior jerárquico, un compañero de trabajo o un cliente; que el 75 por 100 de las mujeres que ejercen profesiones que requieren una cualificación específica u ocupan un puesto directivo han sido víctimas de acoso sexual; que el $61 \%$ de las mujeres en el sector servicios han sufrido acoso sexual; que, en conjunto, entre el 5\% y el 10\% de los trabajadores europeos son víctimas en algún momento, de acoso psicológico en el trabajo".

${ }^{47}$ Vid., ALTÉS TÁRREGA, J.A., El acoso del trabajador en la empresa, op. cit.; BALLESTER PASTOR, M. A., Guía sobre ... op., cit., pp. 13-14; ESPEJO MEGÍAS, P., Hacía una reformulación de la violencia de género..., op. cit., pp. 155-158; PÉREZ DEL RIO, T., "La violencia de género...", op. cit., p. 125.

${ }^{48}$ STS (penal) 101/2019, de 30 de junio (Rec. 31/2018) interesante en cuanto a la distinción entre abuso de poder y acoso sexual; STS (penal), de 8 de junio (Rec. 53/2018); sobre acoso laboral y sexual sobre el grado de fiabilidad de los testimonios; STS (penal), de 22 de octubre de 2015 (Rec. 888/2015) sobre acoso sexual por Guardia Civil y responsabilidad subsidiaria del Estado; STS (penal), de $1^{\circ}$ de julio de 2019 (Rec. 1032/2018) sobre la credibilidad del testimonio de la víctima; STS (militar), de 30 de junio de 2019 (Rec. 31/2018) que establece que se trata de abuso de poder y no de acoso pues se trata de situaciones "que forman parte del devenir diario de todo acuartelamiento"; SAP de Madrid (penal) de 17 de mayo de 2011 (Rec. 78/2010).

${ }^{49}$ Puede verse, la STEDH, de 18 de julio de 2019 (demanda 40311/10), sobre tres mujeres rusas que denunciaron ser víctimas de trata y fueron obligadas a prostituirse.
} 
proceda”. Es muy interesante la protección que pretende el Convenio frente la violencia y acoso en el trabajo causada por terceros ajenos a la relación laboral, tradicionalmente denominada violencia externa. En este sentido, la OIT estableció en 2003 determinadas Recomendaciones practicas sobre la violencia en el trabajo en el sector servicios y medidas para combatirla ${ }^{50}$. En España contamos con el Protocolo de actuación en la Administración General del Estado sobre violencia externa de $2015^{51}$, relativo principalmente a la ejercida por terceros, generalmente usuarios de los servicios, contra empleados públicos durante o como consecuencia del ejercicio de sus funciones legítimamente atribuidas (art. 2 b). Asimismo, pueden señalarse otros puestos de trabajo susceptibles de sufrir una mayor incidencia de situaciones de violencia causada por terceros: a) trabajos realizados en franjas horarias de escasa frecuencia de compañeros, clientes, usuarios y/o público en general, por ejemplo, los realizados en horario nocturno, fines de semana, periodo de vacaciones o de descanso, etc. (servicios de mantenimiento, limpieza, seguridad y otros); b) trabajos en los que se está en contacto con objetos de valor o moneda (joyerías, establecimientos financieros, cobradores de servicios y/o productor, etc.); c) trabajos con colectivos problemáticos o conflictivos (establecimientos penitenciarios, de reinserción de menores, psiquiátricos, etc.); d) trabajos de seguridad y de inspección: se trata de trabajos que están dirigidos a constatar el cumplimiento de normativa, cumplir órdenes legales o que pueden conllevar una actuación sancionadora ${ }^{52}$.

\subsection{Las personas o grupos más susceptibles de sufrir violencia y acoso en el trabajo}

Uno de los debates más polémicos en torno al contenido de la norma internacional giró en torno a la conveniencia o no de incluir una relación de los grupos de personas más susceptibles de ser víctimas de acoso y violencia en el trabajo. El Convenio OIT 190 busca que su normativa se aplique a todos, con independencia de la existencia de grupos vulnerables. En este sentido, el Informe de la OIT sobre Violencia contra las mujeres y los hombres en el mundo del trabajo de 2016 (p. 33) señalaba que no debía reducirse el análisis a una simple lista sobre quien es más vulnerable a la violencia o el acoso pues esta opción llevaría a pensar equivocadamente que las personas son transformadas en víctimas en función de quienes son y lo que hacen. Lo importante es no estigmatizar grupos o personas en función de sus concretas características y/o su pertenencia a un grupo determinado.

Se ha apuntado que es importante no confundir vulnerabilidad con debilidad ${ }^{53}$. La vulnerabilidad es transitoria y está provocada por una incorrecta e insuficiente protección. La vulnerabilidad puede y debe ser erradicada, puede afectar a todos. Es decir, todos los trabajadores y empleadores, independientemente de sus características personales y del trabajo que realizan, y del grupo o grupos "de vulnerabilidad" en los que podrían quedar encuadrados, pueden, en determinadas situaciones y en función de determinados factores y fuentes de riesgo, verse expuestos a la violencia y el

\footnotetext{
${ }^{50}$ Reunión de expertos para elaborar un repertorio de recomendaciones prácticas sobre la violencia y el estrés en el trabajo en el sector servicios: una amenaza para la productividad y el trabajo decente (8-15 octubre 2003), Ginebra.

${ }^{51}$ Fruto del Acuerdo adoptado en Consejo de Ministros de 20 de noviembre de 2015. Puede verse también el listado de factores de riesgos relacionados con este tipo de violencia previstos en la Nota Técnica de Prevención no 489 del INSH, que cita el mencionado Protocolo, relativa, por un lado, a factores del entorno y del lugar de trabajo (localización geográfica del centro de trabajo, diseño, iluminación, visibilidad, acceso, mobiliario y medidas de seguridad) y, por otro, a los procedimientos de Trabajo (horarios, gestión de acceso al público, de dinero, de espera y colas, de quejas y reclamaciones, sistema de entregas y de repartos, calidad de los servicios, trabajo en solitario o en lugares remotos, trabajo con personas problemáticas, preparación para hacer frente a los conflictos, calidad y ritmo de trabajo y disponibilidad de procedimientos de emergencia, entre otros.

${ }^{52}$ GARCÍA JIMÉNEZ, M., "Violencia externa en el lugar de trabajo...”, op. cit., pp. 112-13.

${ }^{33}$ FERNÁNDEZ VILLAZÓN, L. A.; "Grupos vulnerables: apuntes para un concepto jurídico social”, RTSS CEF, núm. 404 (noviembre 2016), p. 115.
} 
acoso. Ello sin perjuicio de que el propio art. 6 del Convenio menciona que las normas nacionales y las políticas que puedan adoptarse a este nivel deben garantizar el derecho a la igualdad y la no discriminación a personas pertenecientes "a uno o varios grupos vulnerables, o a grupos en situación de vulnerabilidad que estén afectados de manera desproporcionada por la violencia y el acoso en el mundo del trabajo".

Es en la Recomendación OIT no 206 que acompaña al Convenio donde se específica que los sectores, ocupaciones y modalidades más expuestos a la violencia y el acoso son los siguientes: el trabajo nocturno, el trabajo que se realiza de forma aislada, el trabajo en el sector de la salud, la hostelería, los servicios sociales, los servicios de emergencia, el trabajo doméstico, el transporte, la educación y el ocio (punto 9). Esta Recomendación, además de expresar una preocupación general por las "consideraciones de género" (punto 2) y varias específicas para las "víctimas de violencia y acoso

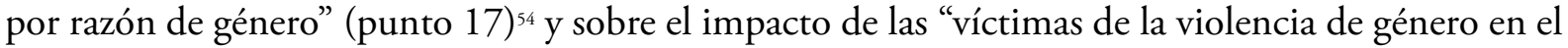
ámbito del trabajo" (punto 18) ${ }^{55}$, menciona: por un lado, a los trabajadores migrantes (punto 10); y, por otro, a los trabajadores y empleadores de la economía informal y sus asociaciones (punto 11).

\subsubsection{Trabajadores migrantes}

En cuanto a los trabajadores migrantes, la Recomendación no 206 establece la conveniencia de que los Estados adopten medidas legislativas y de otra índole para proteger a los trabajadores migrantes y, en particular, a las trabajadoras migrantes contra la violencia y el acoso en el mundo del trabajo, con independencia de su estatus migratorio, en los países de origen, tránsito o destino, según proceda $^{56}$. Como apunta la doctrina, no es frecuente que lleguen a los tribunales cuestiones relativas a la violencia y acoso en el trabajo por motivos xenófobos ${ }^{57}$, y ello es sorprendente dado que las plantillas de las empresas son cada vez más multiculturales, especialmente en determinados sectores como la agricultura y la hostelería. Son muchos los informes que alertan del incremento de los delitos de odio por motivos xenófobos que se traducen en acoso y violencia hacía los trabajadores inmigrantes ${ }^{58}$. Sin olvidar que las diversas formas de violencia y acoso las sufren, en especial, las trabajadoras inmigrantes.

${ }^{54} \mathrm{El}$ apoyo, las vías de recurso y reparación para las víctimas de violencia y acoso por razón de género... deben comprender medidas tales como: a) apoyo a las víctimas para reincorporarse en el mundo del trabajo; b) servicios accesibles, según proceda, de asesoramiento e información; c) un servicio de atención telefónica disponible 24 horas; d) servicios de emergencia; e) la atención y tratamientos médicos y apoyo psicológico; f) centros de crisis, incluidos los centros de acogida; g) unidades especializadas en la policía o agentes con formación específica para ayudar a las víctimas.

${ }^{55}$ Entre las medidas para mitigar el impacto de la violencia doméstica en el mundo del trabajo se podrían incluir: a) licencia para las víctimas de la violencia de género; b) modalidades de trabajo flexible y protección para las víctimas de violencia doméstica; c) protección temporal para la víctimas de violencia de género por despido ,salvo que el motivo del mismo no esté relacionado con la violencia de género; d) la inclusión de la violencia doméstica en la evaluación de riesgos en el lugar de trabajo; e) un sistema de orientación hacia mecanismos públicos de mitigación de la violencia doméstica; y f) la sensibilización sobre los efectos de la violencia doméstica.

${ }^{56}$ Vid., HERRERA RUÍZ, S., "La violencia de género invisibilizada bajo la categoría de migración económica en mujeresmadres centroamericanas", Revista Ciencias Sociales y Humanidades, vol. 4, núm. I-2017; PERKINS, R., "Violencia sexual: un caso para la relajación de los controles fronterizos” PURE Insights, vol. 7, article 9, 2018; BARJA CORIA, J., “¿Por qué si hay tanta violencia en el camino ellas siguen migrando? Antropología, violencia y migración”, ALTERIDADESA, 2019, 29 (58), pp. 17-30.

${ }^{57}$ MINARRO YANINI, M., "El acoso discriminatorio racial o étnico: entre disciplina y prevención de un riesgo psicosocial emergente en empresas multiculturales. Comentario a la STSJ de Murcia 781/2019, de 26 de junio", RTSS. CEF 437-438 (agostoseptiembre 2019), p. 184.

${ }^{58}$ Vid., Informe Raxen especial 2018, Racismo, Xenofobia, Islamofobia, Neofascismo y otras manifestaciones de intolerancia a través de los hechos, elaborado por el Movimiento contra la Intolerancia; y el Informe sobre la evolución de los delitos de odio en España 2018 sobre los incidentes registrados por el Ministerio del Interior. De los 1598 hechos registrados en 2018: 531 se refieren a racismo/ xenofobia; 596 a ideología; 259 a orientación sexual e identidad de género. 


\subsubsection{Trabajadores y empleadores de la economía informal}

En cuanto a los trabajadores y empleadores de la economía informal, el punto 11 de la Recomendación OIT señala que, "al facilitar la transición de economía informal a la formal, los Miembros deberían proporcionar recursos y asistencia a los trabajadores y empleadores de la economía informal, y a sus asociaciones, para prevenir y abordar la violencia y el acoso en ésta”. Tradicionalmente, la OIT ha utilizado el término economía informal para referirse a las actividades económicas que -en la legislación y en la práctica- no están cubiertas o están insuficientemente cubiertas por los sistemas formales $^{59}$. El trabajo en la economía informal crece cada ańo en determinados países en los que la economía no genera empleos suficientes, aumentando en consecuencia el número de trabajadores y empleadores sin garantías laborales ni de seguridad social ${ }^{60}$. Se ha señalado que sería más apropiado el concepto trabajo precario que incluye a la economía informal, el trabajo informal, el trabajo no registrado y otras formas específicas o particulares de empleo ${ }^{61}$. En cualquier caso, se trata de una realidad de inmensa entidad que requiere una actuación integral, no sólo con ocasión de la violencia y acoso en el trabajo, que también, sino en cuanto a su desprotección en términos generales en la línea de encuadrar los problemas en el ámbito del trabajo decente.

\subsection{El lugar de trabajo a efectos de aplicación de la normativa}

En cuanto al concepto de "lugar de trabajo" a efectos de aplicación de la normativa OIT, ha de destacarse la amplitud de este concepto; en este sentido, lo dispuesto en el art. 3 del Convenio:

a) El lugar de trabajo "incluye espacios públicos y privados" cuando sean lugar de trabajo. En el acceso de la Inspección de trabajo al lugar de trabajo juega como límite el derecho a la inviolabilidad del domicilio (art. $18 \mathrm{CE}$ ) aplicable a los casos de despachos, habitación de hotel o similar para lo que se requerirá consentimiento expreso o autorización judicial de la persona afectada.

b) También se consideran lugar de trabajo: "el lugar donde se paga al trabajador, donde éste toma su descanso o donde come, o en los que utiliza instalaciones sanitarias o de aseo y en los vestuarios. Habrá que plantearse como casa con el derecho a la intimidad y hasta que punto se puede grabar a un trabajador con una cámara sin su consentimiento al menos tácito, y como esta grabación puede ser admitida como prueba en un procedimiento judicial.

c) Los desplazamientos hacia y desde el trabajo, los viajes, los eventos o actividades sociales o de formación relacionados con el trabajo, también se asimilan al "lugar de trabajo". De nuevo no va ser fácil identificar la línea divisoria que marque los límites entre la esfera privada y la esfera pública -laboral- de una persona.

d) También se encuentra incluido en el concepto lugar de trabajo, a efectos de aplicación de la normativa internacional, "al marco de las comunicaciones que estén relacionadas con el trabajo, incluidas las realizadas por medio de tecnologías de la información y de la comunicación.

\footnotetext{
${ }^{59}$ La medición de la informalidad: Manual estadístico sobre el sector informal y la economía informal, Centro de Formación de la OIT, Turín, 2013.

${ }^{60}$ RAMOS SOTO, A. L., "Sector informal, economía informal e informalidad", Revista Iberoamericana para la Investigación y el desarrollo educativo RIDE, vol. 6, núm. 11, julio-diciembre 2015, p. 8. Datos de México en 2014, el 57,8 por 100 de la población ocupada se desempeña en actividades informales.

${ }^{61}$ NEFFA, J. C., "Sector informal, precariedad...”, op. cit., p. 21.
} 
Con estas palabras en el Convenio se está haciendo referencia implícita al ciberacoso como forma de violencia y acoso, incluso más allá del estricto ámbito laboral ${ }^{62}$. Que se reconozca que la violencia y acoso pueden tener lugar más allá del lugar físico del trabajo es claramente muy significativo por los muchos retos que plantea en la actualidad, y lo hará en mayor medida en el futuro, el hecho de trabajadores vinculados con su lugar de trabajo por medio de la tecnología: trabajo en plataformas digitales, teletrabajo, trabajo a distancia, etc. Como señalara la OIT en 2006 ${ }^{63}$, la intimidación o el acoso puede realizarse a través del correo electrónico, mensajes telefónicos o subiendo contenidos a la web. Como estas actuaciones pueden realizarse fuera o dentro del espacio físico de trabajo, en horario o no de trabajo, puede inducir a error en cuanto a su consideración o no como violencia y acoso en el trabajo.

Se señala, por último (art. 2.2), que el Convenio se aplica en los lugares de trabajo que pertenecen a todos los sectores, público o privado, de la economía formal como informal, en zonas urbanas o rurales. Es llamativa, desde una perspectiva occidental europea, la referencia a la economía informal que, frente a la formal, la asimilamos como economía no regulada, es decir presumiblemente ilegal. Ya se ha señalado, que el sector informal está formado por empresas, actividades y trabajadores que operan fuera del marco legal pero no por ello su actividad es ilegal; simplemente no está regulada y, generalmente, no se goza, desde el punto de vista de los trabajadores, de una protección laboral y de seguridad social. Se trata de micro-negocios u operaciones a pequeña escala y, en la mayoría de los casos, el negocio no tiene un estatus propio o independiente del dueño o persona que lo conduce.

\section{Consideraciones finales}

De llegar a ratificarse el Convenio OIT 190, tendrá que prevalecer un concepto único de violencia y acoso en el trabajo, lo que desde el punto de vista de nuestro sistema jurídico significará la necesidad de reorganizar y actualizar los conceptos existentes en nuestras distintas normas. Se podría optar simplemente por ratificar el Convenio sin mayores modificaciones legales pero ello seguramente causaría una mayor confusión a la vista de los distintos conceptos legales, doctrinales y jurisprudenciales sobre violencia y acoso en el trabajo con los que nos encontramos. La ratificación del nuevo Convenio OIT 190 sería una buena oportunidad para poner solución al enredo conceptual actual sobre los elementos que delimitan los diferentes comportamientos y conductas y los daños que causan y/o son susceptibles de causar.

Puesto que la violencia y el acoso en el trabajo son objeto de regulación segmentada, el objetivo sería ir reconstruyendo una categoría común y poder elaborar a partir de ella elementos comunes a todos los tipos. Ello permitiría identificar los puntos de conexión entre una figura general y los derechos fundamentales. Además, sería la vía para distinguir la violencia y el acoso de otras figuras como el conflicto laboral y el abuso de poder. Se ha señalado ${ }^{64}$ que existen elementos comunes a todas las formas de violencia y acoso laboral: 1) conducta antijurídica que lesiona de manera directa y efectiva un bien jurídico protegido; 2) en todas las modalidades de violencia y acoso entra en juego y se lesiona un derecho fundamental; 3) en todas sus manifestaciones la víctima es parte de una re-

${ }^{62}$ Vid., GARCÍA GONZÁLEZ, J., (coord..), Ciberacoso: la tutela penal de la intimidad, la integridad y la libertad sexual en Internet, Tirant Monografías no 696, Tirant Lo Blanch, Valencia, 2010; RAMOS QUINTANA, M. I., "Enfrentar la violencia y el acoso en el mundo del trabajo: la discusión normativa de la OIT", Revista del Ministerio de Empleo y Seguridad Social, n 138 , 2018, p. 100.

${ }^{63}$ Informe de la OIT sobre Ciberacoso (2006).

${ }^{64}$ VALDÉS DAL-RÉ, F., “Derecho constitucional y violencia en el trabajo...”, op. cit., p. 12 
lación jurídica contractual, bien una relación laboral, administrativa o de otro tipo. Sin embargo, el agresor puede no ser la otra parte (la imputación de la autoría variará en función de la posición que el agredido ocupa respecto del sujeto agredido); y 4) en cuanto al carácter locativo o espacial, viene discutiéndose si el agresor ha de formar parte o no de la organización. En este sentido, debe tenerse presente la amplitud de los conceptos de trabajador y de lugar de trabajo, incluyéndose la violencia o acoso externo, así como la amplitud de la norma internacional en punto a la aplicación a "otras personas relacionadas con el mundo del trabajo". La totalidad de los comportamientos de violencia ejercidos en lugares de trabajo lesionan derechos fundamentales como la dignidad humana (art. 10.1 CE) y el derecho a la integridad física y moral (art. $15 \mathrm{CE}$ ). Algunas concretas manifestaciones de violencia y acoso pueden, además, vulnerar el derecho a la salud (art. 43.1 CE), la prohibición contra la discriminación (art. $14 \mathrm{CE}$ ) e, incluso como en el caso del acoso sexual, el derecho a la intimidad (art. 18.1 CE).

Quizás debería plantearse ir abandonando la tradicional distinción entre acoso moral y acoso discriminatorio pues todo tipo de violencia y acoso es un acto de discriminación y, sobre todo, un ataque a la dignidad de las personas. Claramente no se requiere en este momento normativizar el concepto acoso moral pues, en especial a partir de la STC 56/2019, y si se produce la ratificación del Convenio OIT 190, futuros pronunciamientos judiciales sobre el acoso moral deberían seguir la línea de ruptura iniciada a partir de esta sentencia. En ambos casos -STC 56/2019 y Convenio OIT- se apuesta por un concepto amplio, que debe tener como referencia principal la protección de la persona que presta servicios por cuenta ajena "frente a toda conducta que pueda poner, porque así lo quiera o porque así resulte, en peligro su integridad y dignidad (arts. 10.1 y 15 CE)". "Y ello al margen de cuál sea la intencionalidad y la mayor o menor legitimidad de sus fines, pues la prohibición es absoluta" ${ }^{65}$. Ni el elemento subjetivo (intencionalidad), ni el elemento reiteración, ni el elemento de resultado (producción efectiva y acreditada de un daño) deben exigirse como constitutivos del tipo jurídico acoso laboral en la doctrina constitucional a partir de la STC 56/2019, como tampoco lo son en el concepto previsto en el Convenio OIT 190 (art. 1.1.a) y tampoco deberían serlo si se produce la ratificación del mismo.

En la norma internacional tampoco se menciona que haya de producirse un daño extremo pues se mencionan exclusivamente distintos tipos de daño (físico, psicológico, sexual o económico) sin cuantificar cuánto daño, ni de que magnitud ha de ser ese daño, para ser constitutivos del tipo ${ }^{66}$. En nuestro sistema, la vía penal es la utilizada para castigar las situaciones de acoso más graves (art. 173.1 Código Penal), que prevé el acoso y violencia vertical (entre superior jerárquico y trabajador) pero no el horizontal (entre compañeros u otros). También en este punto habrá que introducir seguramente modificaciones legales.

Con respecto a los conceptos violencia y acoso por razón de género, pienso que habría que replantearse su evolución hacía un concepto más genérico como violencia contra las mujeres e incidir en la vertiente de la violencia económica tradicionalmente ejercida sobre las mujeres y sus implicaciones en el mundo laboral. Con ello no quiere decirse que haya que obviar la muy necesaria tutela del derecho fundamental de las mujeres a no sufrir discriminación por razón de sexo (art. 14 CE). En este sentido la reciente STC de 30 de septiembre de 2019 (Rec. 2925/2018) afirma la finalidad tuitiva y pedagógica de respuesta histórica a favor de la parificación social y jurídica que precisa la población femenina: "es preciso atender a circunstancias tales como la peculiar incidencia que respecto de la situación laboral de aquélla tiene el hecho de la maternidad y la lactancia, en cuanto se

${ }^{65}$ STC 120/1990 (FJ 9), cit., por MOLINA NAVARRETE, C., "La <des-psicologización> del concepto constitucional...”, op., cit., p. 133.

${ }^{66}$ Muy diferente es lo dispuesto en el criterio técnico 69/2009 de la ITSS sobre acoso laboral pues define esta figura como "violencia psicológica extrema" sobre otra persona en su lugar de trabajo. 
trata de compensar las desventajas reales que para la conservación de su empleo soporta la mujer a diferencia del hombre y que incluso se comprueba por datos revelados por la estadística, tal como el número de mujeres que se ven obligadas a dejar el trabajo por esta circunstancia a diferencia de los varones" $\left(\mathrm{FJ} 2^{\circ}\right)$.

Se ha señalado, sin embargo, que la tutela antidiscriminatoria se muestra insuficiente por dos razones $^{6}:$ 1) porque las reacciones frente a conductas discriminatorias sólo pueden tener un carácter restrictivo o sancionador que, en muchas ocasiones, se quedan en el terreno de lo meramente resarcitorio, desde el punto de vista económico, pero no van a las raíces del problema. Por ello las medidas de tutela antidiscriminatoria, deben venir acompañadas de medidas profilácticas y preventivas que corrijan la situación desde su origen, cambiando prácticas empresariales y culturas laborales... los planes de igualdad son decisivos; y 2) porque no se puede intervenir aisladamente en el plano laboral... servicios públicos orientados a la atención de necesidades familiares, un sistema de horarios que tome en consideración las jornadas laborales, unas políticas familiares que fomenten al corresponsabilidad, etc. pueden convertirse en la clave de un trabajo igualitario entre hombres y mujeres, que al final se convierta en piedra angular de un trabajo digno para todos.

El amplio enfoque del Convenio OIT 190 es de gran importancia: todas las personas que trabajan han de quedar protegidas, con independencia de su situación contractual (la norma incluso menciona a los despedidos, los que buscan empleo, etc.) y de sus características personales. Ello es determinante sobre todo en cuanto al acoso tradicionalmente denominado moral y sus repercusiones en la salud de la víctima. Pueden identificarse tres conceptos en los que habrá que profundizar: 1) factor de riesgo psicosocial relacionado con el trabajo: relativo causas o agentes que generan probabilidad de que se den situaciones nocivas (alta demanda de trabajo, presión, estilos autoritarios y machistas de dirección, etc.); 2) riesgos psicosociales en el trabajo (estrés, acoso, violencia, adicciones, etc.); y 3) daños psicosociales con ocasión o a consecuencia del trabajo (síndromes, enfermedades mentales, incapacidades, etc. $)^{68}$.

En línea con lo dispuesto en la normativa internacional, el siguiente paso sería afianzar que la violencia y acoso en el lugar de trabajo sean considerados daños derivados del trabajo, obligando al empresario a adoptar cuantas medidas sean necesarias, al más alto nivel posible, según el espíritu original de la Directiva marco 89/391 sobre seguridad y salud, sin subordinación a consideraciones de tipo económico (exposición de motivos, párrafo 17 Directiva marco), y respetando los derechos de consulta y participación de los trabajadores (art. 11 Directiva marco). En este sentido, pienso que también habría que modificar la LPRL de manera que se asegure una prevención suficiente y eficaz de la violencia y acoso en el trabajo. La LPRL dice que el empresario está obligado a garantizar la seguridad y salud de sus trabajadores "en todos los aspectos relacionados con el trabajo". Ello implica que está obligado a adoptar no solo las medidas previstas en los textos legales sino cualquier otra posible, razonable y necesaria para evitar y prevenir cualquier situación de riesgo (STS 62/2007, de 27 de marzo, Rec. 1623/2002). El objetivo debería ser que no se produjeran situaciones de violencia y acoso. El tema es complejo, sobre todo porque no es fácil delimitar los elementos característicos de la violencia y el acoso. Aceptando que debe prevalecer un concepto único e integral, el problema conceptual es complicado sobre todo porque habrá situaciones en las que, al no producirse un daño físico o psicológico concreto, aunque si se produzca la posibilidad de que se cause, como señala el

\footnotetext{
${ }^{67}$ CRUZ VILLALÓN, J., "La centralidad del trabajo digno en un nuevo modelo social”, Revista Internacional y Comparada de RRLL y Derecho del Empleo, vol. 7, núm. 4, octubre-diciembre 2019, ADAPT University Press, p. 248.

${ }^{68}$ GARCÍA JIMENEZ, M., "La violencia en el ámbito laboral...”, op. cit., p. 109. Señala este autor que los psicólogos han de perfeccionar los instrumentos de evaluación del mobbing con el fin de establecer el nivel a partir del cual se requiere una intervención tanto en el ámbito legal como en el de ayuda psicológica a la víctima. Se han de mejorar los instrumentos de evaluación con el objetivo de lograr estimar un punto de corte objetivo que permita afianzar la existencia de mobbing.
} 
art. 1.1.a del Convenio OIT 190, habría que poner el acento en el daño a la dignidad de la persona, que mas que un derecho fundamental es un metaderech $\sigma^{69}$ o derecho radical, del que traen su causa los demás derechos fundamentales ${ }^{70}$.

\section{Bibliografia}

ACALE SÁNCHEZ, M., "El concepto poliédrico de acoso en el trabajo en el Código Penal: luces y sombras”, Revista de Derecho Social núm. 79, 2017, pp. 63-92.

ALTÉS TÁRREGA, J., El acoso del trabajador en la empresa, Ed. Tirant Lo Blanch, 2008, Valencia, BALLESTER PASTOR, M. A., "La política de la OIT y de la Unión Europea sobre la salud y riesgos psicosociales", Revista Internacional y Comparada de Relaciones Laborales, ADAPT University Press, volumen 1, no 4, octubre-diciembre 2013, pp. 1-23.

BALLESTER PASTOR, M. A., Guía sobre el acoso moral en el trabajo, Guías de Negociación, Consejo Andaluz de Relaciones Laborales, 2006, edición actualizada a la Ley Orgánica 3/2007,

BARJA CORIA, J., "¿Por qué si hay tanta violencia en el camino ellas siguen migrando? Antropología, violencia y migración”, ALTERIDADESA, 2019, 29 (58), pp. 17-30.

BASTIDA DOMÍNGUEZ, M., "Del cristal al acero: nuevas barreras para nuevos tiempos”, RTSS. CEF, núm. 429 (diciembre 2018), pp. 223-262.

BLÁZQUEZ AGUADO, E., "Una aproximación a la igualdad de género en el mercado laboral" en BLÁZQUEZ AGUADO, E., SAINZ DE BARANDA ANDÚJAR, C. y NIETO ROJAS, P. (Dirs.), Especialista en Gestión de Politicas de Igualdad, Thomson Reuters Aranzadi, Cizur Menor, Navarra, 2019, pp. 267-294.

CONESA BALLESTERO, J., y SANAHUJA VIDAL., M., "Acoso moral en el trabajo. Tratamiento jurídico (mobbing)", Actualidad Laboral, no 2, 2002.

CORREA CARRASCO, M., Acoso Laboral. Regulación jurídica y práctica aplicativa, Colección laboral no 258, Tirant Lo Blanch, Valencia, 2019.

CRUZ VILLALÓN, J., "La centralidad del trabajo digno en un nuevo modelo social”, Revista Internacional y Comparada de RRLL y Derecho del Empleo, vol. 7, núm. 4, octubre-diciembre 2019, ADAPT University Press, pp. 234-248.

DIAZ LAFUENTE, J., "El reconocimiento de la identidad de género por el Tribunal de Justicia de la Unión Europea. Comentario a la STJUE de 26 de junio de 2018, asunto C-451/16", RTSS. CEF, núm. 427, octubre 2018.

ESPEJO MEGÍAS, P., Hacía una reformulación de la violencia de género laboral, Madrid Wolters/ kluwer/la Ley, 2018.

FERNÁNDEZ SEGADO, F., “La dignidad de la persona como valor supremo del ordenamiento jurídico", Derecho PUCP (50), 1996, pp. 11-45.

FERNÁNDEZ VILLAZÓN, L. A., "Grupos vulnerables: apuntes para un concepto jurídico social”, RTSS CEF, núm. 404 (noviembre 2016), pp. 109-134.

FERRANDO GARCÍA, M. F., "La discriminación múltiple e interseccional en el ámbito laboral”, RTSS.CEF, núm. 428 (noviembre 2018), pp. 19-54.

\footnotetext{
${ }^{69}$ Concepto acuñado por el economista bengalí AMARTYA SEN (el metaderecho a estar libre de hambre). La dignidad, en su sentido más profundo de inviolabilidad de la persona, es un metaderecho y como tal debe ser protegido incluso frente al consentimiento del propio afectado. Vid., FERNÁNDEZ SEGADO, F., "La dignidad de la persona como valor supremo del ordenamiento jurídico", Derecho PUCP (50), 1996, pp. 11-45.

${ }^{70}$ PECES BARBAS, G., Derechos Fundamentales, Latina Universitaria, Madrid, 1980, p. 91. Cit. por FERNÁNDEZ SEGADO, F., "La dignidad de la persona...", op. cit., p. 19.
} 
GARCÍA GONZÁLEZ, J., (coord..), Ciberacoso: la tutela penal de la intimidad, la integridad y la libertad sexual en Internet, Tirant Monografías no 696, Tirant Lo Blanch, Valencia, 2010.

GARCÍA JIMÉNEZ, M., "Violencia externa en el lugar de trabajo: marco conceptual y caracterización jurídica", Revista Internacional comparada de Relaciones Laborales y Derecho del Empleo, ADAPT University Press, volumen 7, no 2 abril-junio 2019.

GARCÍA TESTAL, E., Derechos de las trabajadoras víctimas de la violencia de género, Colección laboral no 229, Tirant Lo Blanch, Valencia, 2014.

HERRERA RUIZ, S., "La violencia de género invisibilizada bajo la categoría de migración económica en mujeres-madres centroamericanas", Revista Ciencias Sociales y Humanidades, vol. 4, núm. I-2017.

HERRERO MAROTO, S., "El síndrome del boreout y la STC 56/2019 sobre mobbing en la Administración Pública”, Diario La Lay, no 9458, 17 de julio de 2019.

LOUSADA AROCHENA, F., "El Convenio 190 de la Organización Internacional del Trabajo"; RDS no 88, 2020

MAUPAIN, F., The future of the International Labour Organization in the global economy, Oxford, Hart Publishing, 2013.

MEJÍAS GARCÍA, A., "Presión laboral tendenciosa. Medios de protección", en El acoso laboral, antes llamado mobbing, Tirant Monografías no 543, Tirant Lo Blanch, Valencia, 2008

MINARRO YANINI, M., "El acoso discriminatorio racial o étnico: entre disciplina y prevención de un riesgo psicosocial emergente en empresas multiculturales. Comentario a la STSJ de Murcia 781/2019, de 26 de junio", RTSS. CEF 437-438 (agosto-septiembre 2019), pp. 181188.

MOLINA NAVARRETE, C., "La <des-psicologización> del concepto constitucional del acoso moral en el trabajo: ni la intención ni el daño son elementos del tipo jurídico", Revista de Derecho Social no 86, abril- junio 2019, pp. 119-143.

MOLINA NAVARRETE, C., "Identidad europea, brechas de género y protección social: el Tribunal de Justicia de la Unión Europea desnuda persistentes discriminaciones por razón de sexo", RTSS, CEF, 435 (junio 2019), pp. 5-12.

MOLINA NAVARRETE, C., "Del acoso moral (mobbing) al ciberacoso en el trabajo (network mobbing): viejas y nuevas formas de violencia laboral como riesgo psicosocial en la reciente doctrina judicial", Revista de Trabajo y Seguridad Social, CEF, 437-438 (agosto-septiembre 2019), pp. 143-165.

MONTOYA MELGAR, A., "El acoso en el trabajo y su encuadramiento jurídico", Civitas, Revista Española de Derecho del Trabajo no 140, 2008, pp. 751-768.

MORALES RAMÍREZ, M. A., "Aproximación al acoso laboral desde la legislación comparada", Boletín Mexicano de Derecho Comparado, nueva serie, año XLIX, núm. 147, septiembrediciembre de 2016, pp. 71-98.

NEFFA, J.C., Los riesgos psicosociales en el trabajo: contribución a su estudio, Ed. Centro de Estudios e Investigaciones Laborales CEIL-CONICET; Facultad de Ciencias Económicas de la Universidad Nacional de Nordeste de Argentina, entre otros, 2015.

OJEDA AVILÉS, A., "Del mundialismo a la globalización. Un balance de los convenios OIT y su proyección futura”, Revista de Trabajo y Seguridad Social, CEF, 434, 2019.

OLMEDO, M., y GÓNZALEZ, P., "La violencia en el ámbito laboral: la problemática conceptualización del mobbing, su evaluación, prevención y tratamiento", Acción Psicológica, junio 2006, vol. 4, no 2, pp. 107-128.

PECES BARBAS, G., Derechos Fundamentales, Latina Universitaria, Madrid, 1980. 
PÉREZ DEL RIO, T., "La violencia de género en el empleo como violación del derecho a la integridad física y psíquica y su prevención. La función de los interlocutores sociales”, Lan Harremanak/ 25, 2012, pp. 123-154.

PÉREZ DEL RIO, T., La violencia de género en el ámbito laboral: el acoso sexual y el acoso sexista, Albacete, Bomarzo, 2009.

PÉREZ MACHÍO, A., Mobbing y Derecho Penal, Tirant Lo Blanch, Valencia, 2007.

PERKINS, R., "Violencia sexual: un caso para la relajación de los controles fronterizos", PURE Insights, vol. 7, article 9, 2018.

RAMOS QUINTANA, M. I., "Enfrentar la violencia y el acoso en el mundo del trabajo: la discusión normativa de la OIT", Revista del Ministerio de Empleo y Seguridad Social, no 138, 2018, pp. 91-114.

RAMOS SOTO, A. L., "Sector informal, economía informal e informalidad", Revista Iberoamericana para la Investigación y el desarrollo educativo RIDE, vol. 6, núm. 11, julio-diciembre 2015.

RODRÍGUEZ ESCANCIANO, S., "La discriminación retributiva por causa del sexo y género: factores desencadenantes y pautas de solución”, Documentación Laboral, núm. 113-año 2018, Vol. I, pp. 7-30.

SANGUINETI RAYMOND, W., "Las cadenas mundiales de producción y la construcción de un derecho del trabajo sin fronteras", Ponencia Inaugural del XXIX Congreso Anual de la Asociación Española de Derecho del Trabajo y de la Seguridad Social sobre "El futuro del trabajo: cien años de OIT", Salamanca, 30 y 31 de mayo de 2019.

TAMAYO ACOSTA, J. J., "Principales categorías de la teoría de género" en BLÁZQUEZ AGUADO, E., SAINZ DE BARANDA ANDÚJAR, C. y NIETO ROJAS, P. (Dirs.), Especialista en Gestión de Politicas de Igualdad, Thomson Reuters Aranzadi, Cizur Menor, Navarra, 2019, pp. 93-106.

URRUTIKOETXEA BARRUTIA, M., Acoso laboral y lesión de Derechos fundamentales, Bomarzo, 2014.

VALDÉS DAL-RÉ, F., “Derecho constitucional y violencia en el trabajo en España”, Revista Internacional y comparada de Relaciones laborales y derecho del Empleo, Vol. 1, núm. 4, octubrediciembre de 2013, pp. 1-24.

VELÁZQUEZ FERNÁNDEZ, M. P., "El Convenio 190 de la OIT sobre violencia y acoso en el trabajo: principales novedades y expectativas", Revista de Trabajo y Seguridad Social, CEF 437-438 (agosto-septiembre 2018), pp. 57-79.

YUGUEROS GARCÍA, A. J., "La violencia contra las mujeres: conceptos y causas", Revista Castellano-Manchega de Ciencias Sociales, no 18, 2014, pp. 147-159. 